\title{
Probing a Local Viscosity Change at the Nematic-Isotropic Liquid Crystal Phase Transition by a Ratiometric Flapping Fluorophore
}

\author{
Ryo Kimura, ${ }^{a}$ Hidetsugu Kitakado, ${ }^{a}$ Takuya Yamakado, ${ }^{a}$ Hiroyuki Yoshida, ${ }^{* b}$ and Shohei Saito*a \\ ${ }^{a}$ Graduate School of Science, Kyoto University, Kitashirakawa Oiwake, Sakyo, Kyoto 606-8502, \\ Japan. \\ ${ }^{b}$ Graduate School of Engineering, Osaka University, 2-1 Yamadaoka, Suita, Osaka 565-0871, Japan
}

\begin{abstract}
Local viscosity change in the thermal phase transition of a nematic liquid crystal, 5CB, has been analyzed by doping fluorescent viscosity probes, flapping fluorophores (FLAP) as well as a molecular rotor BODIPY-C $\mathrm{C}_{12}$. As a result, only flapping anthraceneimide has successfully monitored a small viscosity change (corresponding to a few cP (centipoise) change in shear viscosity around $25 \mathrm{CP}$ ) in the nematic-to-isotropic phase transition by ratiometric spectroscopy. In addition, analysis of fluorescence anisotropy indicates that the emissive species (planarized flapping anthraceneimides) are aligned parallel to the director of 5 CB in the nematic phase.
\end{abstract}

Analysis of the viscosity of liquid crystals is important not only in basic science ${ }^{[1]}$ but also in applications to displays and microfluidic devices ${ }^{[2]}$. Since low-viscosity nematic liquid crystals have a fast response time to external fields, molecular theory to describe the viscosity of nematic liquid crystals have been widely discussed. ${ }^{[3]} 5 \mathrm{CB}$ (4-cyano-4'-pentylbiphenyl) is one of the most-studied nematic liquid crystal, which shows a thermal phase transition at the clearing point around $35^{\circ} \mathrm{C}$. A discontinuous decrease in shear viscosity (only by a few CP change around $25 \mathrm{cP}$ ) during the isotropic-to-nematic phase transition of 5 CB was reported using a rheometer (Fig. 1a) and discussed along with a small discontinuous increase in density. ${ }^{[4]}$ However, it is challenging to monitor "local viscosity" in a phase transition of LC materials by using fluorescent molecular viscosity probes. Although one example was reported for a fluorogenic molecular rotor to detect a phase transition of a liquid crystal "80B4100", the structure, phase and viscosity value of this liquid crystal were undisclosed. ${ }^{[5]}$ Local viscosity is a different measure from shear viscosity obtained from rheometers. Local viscosity reflects the degree to which ultrafast conformational dynamics of photoexcited molecules is suppressed in a nanoscale environment. While molecular viscosity probes represented by molecular rotors have been widely used for bioimaging technique, ${ }^{[6]}$ applications to monitoring nano-environments of condensed matter have been also demonstrated. $[7,8 \mathrm{a}]$

With this background, we have previously developed flapping fluorophores (FLAP) as a new category of molecular viscosity probe. ${ }^{[8]}$ While conventional molecular rotors probe local viscosity by internal rotation dynamics, the flapping fluorophores sense nano-environments by a bent-to-planar conformational change in the excited state. The flapping fluorophores show high sensitivity particularly in a low viscosity range below 100 cP. ${ }^{[8 a, 8 c-e]}$ Very recently, a modified flapping (a)

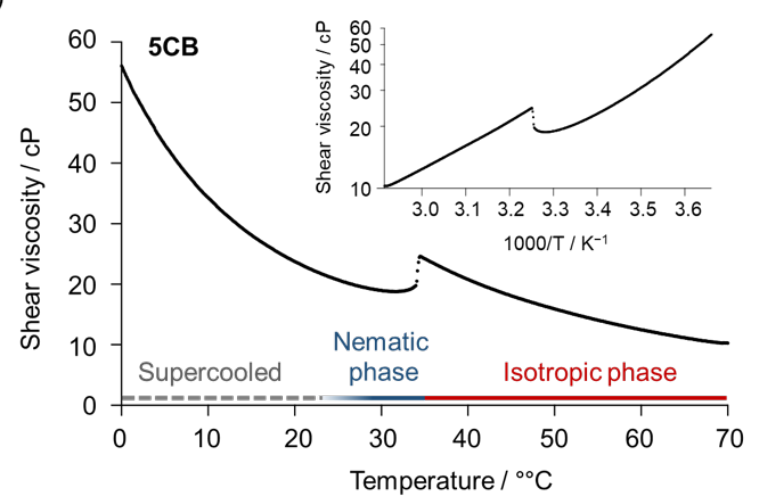

(b)

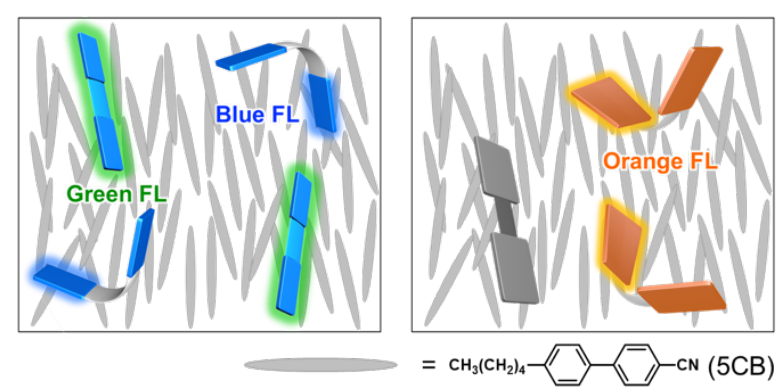

Fig. 1. (a) Temperature-dependent shear viscosity of $5 C B$, measured in a cooling process $\left(6^{\circ} \mathrm{C} / \mathrm{min}\right)$ by a rheometer. (inset) Andrade plot (b) Schematic representation of a nematic liquid crystal doped with viscosity-probing flapping fluorophores FLAPO (ratiometric probe; left) and FLAP1 (fluorogenic probe; right), in which photoexcited molecules are partially planarized.

probe even realized real-time monitoring of dynamic polymer free volume by single-molecule fluorescence spectroscopy. ${ }^{[8 f]}$ Here, we report the attempts to monitor the local viscosity change in the thermal phase transition of $5 \mathrm{CB}$, using flapping fluorophores (Fig. 1b) as well as a commonly-used molecular rotor, BODIPY-C $\mathbf{C}_{\mathbf{1 2}}{ }^{[6 a, 9]}$ Furthermore, we have analyzed anisotropy in the absorption/fluorescence of the FLAP-doped $5 C B$ with uniaxial alignment to gain insight into the orientation of the FLAP molecules in a liquid crystal. 

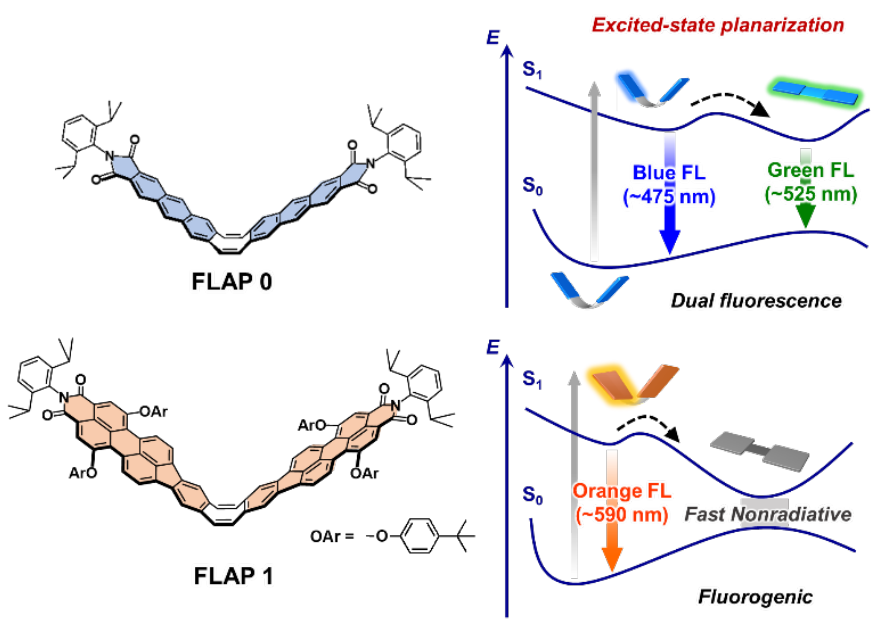

Fig. 2. Flapping anthraceneimide FLAPO and flapping peryleneimide FLAP1 (left). Dual fluorescence properties of FLAPO and fluorogenic properties of FLAP1 are demonstrated with their energy profiles of the ground state $\left(S_{0}\right)$ and the excited state $\left(S_{1}\right)$ (right).

FLAPO ${ }^{[8 a-8 c]}$ and FLAP1 ${ }^{[8 \mathrm{~d}, 8 \mathrm{e}]}$ were synthesized according to the reported protocols. Since their planarization dynamics and an accompanying electronic configurational switch in $\mathrm{S}_{1}$ are sensitive to local environments, both FLAP0 and FLAP1 work as a viscosity probe in a low viscosity range (below $100 \mathrm{cP}$ ). However, a subtle difference in their $S_{1}$ excited state profiles leads to the distinct spectroscopic responses. FLAPO shows a bright green FL emitted from the planar geometry (Fig. S4-5) in low-viscosity media, while the intensity of the blue fluorescence (FL) derived from the V-shaped geometry (Fig. S44) increases in high-viscosity media due to the suppression of the planarization in the excited state. ${ }^{[8 a]}$ Polarity-independence has also been confirmed in the ratiometric FL of FLAPO. On the contrary, FLAP1 does not show FL from the planar geometry due to fast nonradiative decay. However, the $S_{1}$ conformational planarization of FLAP1 is significantly suppressed by increasing viscosity, and it works as a fluorogenic viscosity probe. A pronounced FL enhancement and a prolonged $\mathrm{FL}$ lifetime are observed in a viscous media even less than $3 \mathrm{CP} .{ }^{[8 \mathrm{~d}, 8 \mathrm{e}]}$ BODIPY- $\mathrm{C}_{12}$ is categorized as a fluorogenic molecular rotor. Since the dynamic internal rotation in $S_{1}$ is suppressed in highly viscous media, FL quantum yield increases with bright green $\mathrm{FL}$ and FL lifetime prolongs. ${ }^{[6 a, 9]}$

We started experiments from FL measurements of the three molecular viscosity probes in 5 CB (ca. 20-cP viscosity at $25^{\circ} \mathrm{C}$ ) and in benzonitrile ( $\mathrm{PhCN} ; 1.2-\mathrm{CP}$ viscosity at $25^{\circ} \mathrm{C}$ ), which is a reference solvent bearing a similar dipole moment to $5 \mathrm{CB}$ (Fig. 3, See Chapter 1 in the SI for details). The ratiometric probe FLAPO shows a smaller FL ratio of $I_{528} / I_{475}(=3.9)$ in 5 CB than in $\mathrm{PhCN}$ (9.2). This indicates that the planarization in $S_{1}$ is partially suppressed due to higher viscosity of $5 C B$ and the blue fluorescence from the $\mathrm{V}$-shaped conformer was observed more significantly. On the other hand, the fluorogenic probe FLAP1 display a large difference in FL quantum yield and FL lifetime. In $\mathrm{PhCN}$, the FL quantum yield ( $\Phi_{\mathrm{F}}$ ) of FLAP1 was 0.008 and the fluorescence lifetime $\left(\tau_{\mathrm{F}}\right)$ was about $0.2 \mathrm{~ns}$, whereas, in $5 \mathrm{CB}, \Phi_{\mathrm{F}}$ increased more than 10 times to 0.11 and $\tau_{\mathrm{F}}$ also prolonged to $1.1 \mathrm{~ns}$. The similar tendency was observed for BODIPY- $\mathrm{C}_{12}\left(\Phi_{\mathrm{F}}=\right.$ $0.056, \tau_{\mathrm{F}}=0.62 \mathrm{~ns}$ in $\mathrm{PhCN}$ and $\Phi_{\mathrm{F}}=0.26, \tau_{\mathrm{F}}=2.2 \mathrm{~ns}$ in $\left.5 \mathrm{CB}\right)$. These results also indicate that the planarization of FLAP1 as well as the internal bond rotation of BODIPY- $\mathrm{C}_{12}$ is partially (a)

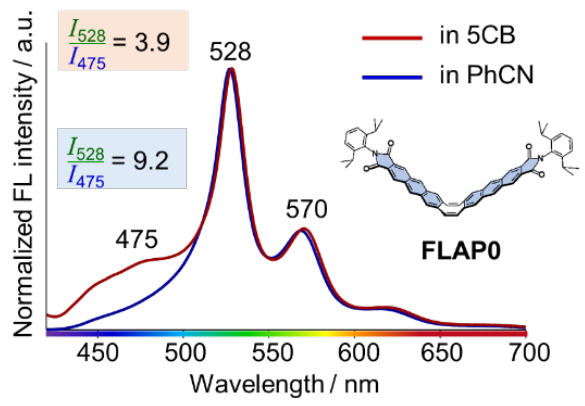

(b)

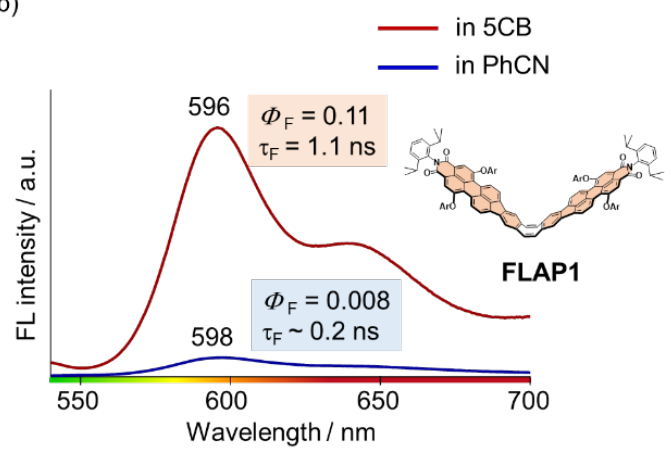

(c)

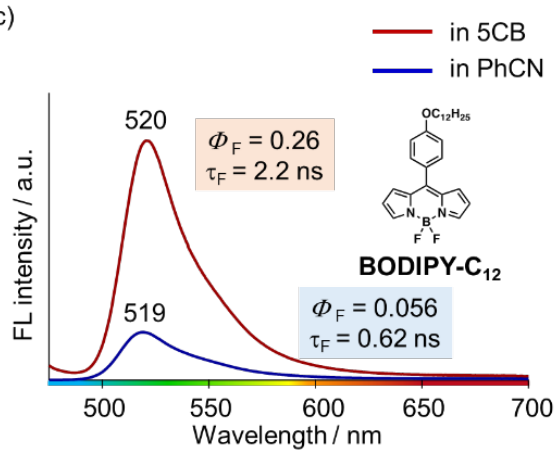

Fig. 3. FL properties of (a) FLAPO $\left(\lambda_{\mathrm{ex}}=405 \mathrm{~nm}\right)$, (b) FLAP1 $\left(\lambda_{\mathrm{ex}}=520\right.$ $\mathrm{nm})$, and (c) BODIPY- $\mathrm{C}_{12}\left(\lambda_{\mathrm{ex}}=460 \mathrm{~nm}\right)$ in $5 \mathrm{CB}$ and in PhCN. Concentration of the viscosity probes $<10^{-4} \mathrm{M}$. Non-polarized excitation with no analyzer in a standard quartz cuvette $(1.0 \mathrm{~mm})$.

suppressed in viscous $5 \mathrm{CB}$. In other words, the difference of local viscosity between PhCN and $5 \mathrm{CB}$ was detectable with all three probes.

Next, temperature dependence of the FL properties was studied in 5CB (Fig. 4). The concentration of the fluorescent probes is in the order of $10^{-5} \mathrm{M}$ (less than $10^{-2} \mathrm{wt} \%$ ), which has no influence on the thermal phase transition of 5 CB (Fig. S2-7). As the temperature increased over the clearing point of $5 \mathrm{CB}$ (isotropic phase), the $\mathrm{FL}$ ratio of $I_{528} / I_{475}$ continuously increased in FLAPO, and the fluorescence lifetime became shorter in FLAP1. On the other hand, a rigid peryleneimide fluorophore Wing1, which is a reference compound of flexible FLAP1, showed almost constant FL lifetime in the higher temperature range (Fig. S2-5). These results clearly indicate that the observed FL responses of FLAP are derived from the flexible motion, and that the planarization dynamics in $\mathrm{S}_{1}$ is promoted in higher temperature. BODIPY- $\mathrm{C}_{12}$ also showed the similar 
(a)

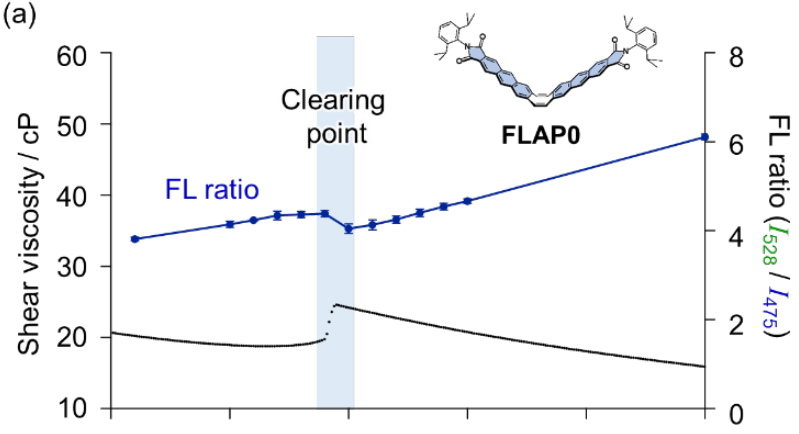

(b)

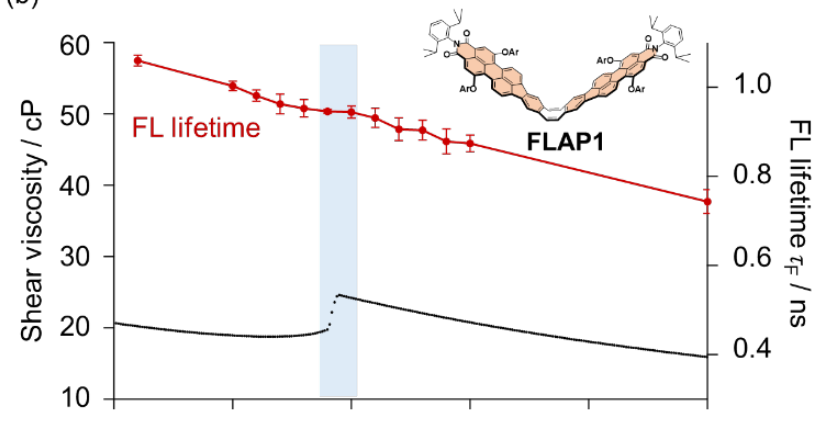

(c)

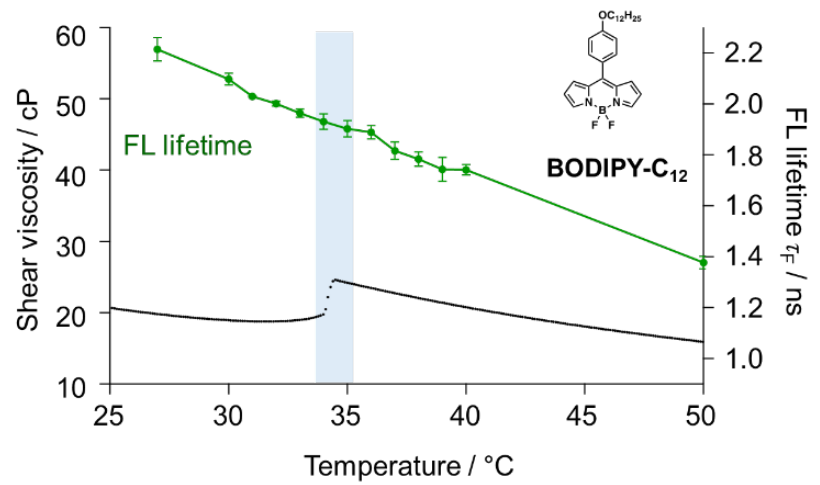

Fig. 4. Temperature-dependent (a) FL ratio of FLAPO, (b) FL lifetime of FLAP1, and (c) FL lifetime of BODIPY- $\mathrm{C}_{12}$ doped in 5CB. Each measurement was performed when the temperature remains constant for 5-10 min after the gradual heating. Measurements were performed 3 times to display sample standard deviation.

tendency with FLAP1. Interestingly, these tendencies of the three probes are also consistent in the temperature range below the clearing point (nematic phase). However, more importantly, only FLAPO displayed a characteristic discontinuous change in the $I_{528} / I_{475} \mathrm{FL}$ ratio at the nematic-toisotropic phase transition of $5 \mathrm{CB}$, whereas FLAP1 and BODIPY$\mathrm{C}_{12}$ did not detect the phase transition by the $\mathrm{FL}$ lifetime measurement. The values of the FL ratio $\left(/_{528} / /_{475}\right)$ using FLAPO was $4.4 \pm 0.1$ at $34{ }^{\circ} \mathrm{C}$ and $4.0 \pm 0.1$ at $35^{\circ} \mathrm{C}$. The significant decrease of the $\mathrm{FL}$ ratio over the narrow temperature range can be attributed to the detection of a nano-environmental change by the phase transition. Since FLAPO has the polarity independence in a wide range of dielectric permittivities, ${ }^{[8 a, 8 c]}$ the decrease of the FL ratio can be mainly assigned to the increase in "local viscosity" around the clearing point in the nematic-to-isotropic phase transition. Namely, the planarization dynamics of FLAPO in the excited state become slightly more suppressed when the nematic $5 C B$ turns isotropic at the clearing point. It is noteworthy that the shear viscosity measured by a rheometer also increased in the nematic-toisotropic phase transition. The agreement supports the close relationship between the macroscopic and microscopic (local) viscosities, which has been recognized as Förster-Hoffman (F$\mathrm{H}$ ) equation (Fig. S2-4), ${ }^{[6 a, 6 b, 9]}$ particularly in Newtonian fluids. The efficacy of FLAPO over BODIPY- $\mathrm{C}_{12}$ for the detection of the phase transition would originate from the different motions for the viscosity sensing (flapping vs rotation) and the gap of the required free volumes for the dynamic conformational change. ${ }^{[8 f]}$ On the other hand, the unsuccessful detection by FLAP1 would be simply due to the saturated viscosity response below $20 \mathrm{cP} .{ }^{[8 \mathrm{e}]}$

Anisotropy in the absorption/FL of FLAPO in a uniaxially aligned $5 C B$ was investigated by micro-spectroscopy to gain insight into the molecular orientation of FLAPO in the liquid crystal host (see Fig. S3-1 for details of the measurement). Here, FLAPO was doped in 5 CB at a weight ratio of $0.5 \mathrm{wt} \%$ or $1 \mathrm{wt} \%$, and the mixture was filled in a glass sandwich cell with uniaxial rubbing treatment. Measurement of polarized absorbance spectra showed a small anisotropy along the LC director that disappeared in the isotropic phase (Fig. S3-2), indicating that the orientation of the V-shaped FLAPO molecules is not isotropic in the ground state (See the transition dipoles in Fig. S4-2). Upon non-polarized excitation at approx. $380 \mathrm{~nm}$, the emission was anisotropic with stronger intensity along the director, and interestingly, the intensity ratio of the emission peaks (FL ratio) varied depending on polarization (Fig. 5, Fig. S3-3). Whereas the blue emission peak at $475 \mathrm{~nm}$, attributed to the V-shaped FLAPO showed a fluorescent dichroic ratio of $I_{/ /} / I_{\perp}=1.6$, the green emission peak at $528 \mathrm{~nm}$, attributed to the planarized FLAPO, showed a larger value of $I_{/ /} / I_{\perp}=2.5$, causing the $I_{528} / I_{475}$ intensity ratio to vary between 1.8 and 1.2. The anisotropy disappeared in the isotropic phase (Fig. S3-4), suggesting that the nematic order causes the planarization of FLAPO to occur preferentially along the nematic director. In fact, it is well known that the viscosity of liquid crystals is anisotropic and depends on the relative directions of the director ${ }^{[3]}$; it is therefore natural for the "local viscosity" to also be anisotropic and depend on the relative orientations of the fluorescent probe and the director. Measurement of the non-polarized fluorescence spectrum upon polarized excitation also supported the anisotropy in planarization probability, giving a larger $I_{528} / I_{475}$ ratio for excitation polarized along the director (Fig. S3-5). Since the planarization rate of FLAPO is much faster (subnanoseconds in its time constant) than the spectral acquisition rate in these measurements, further investigation employing ultrafast pumpprobe experiments ${ }^{[10]}$ as well as molecular dynamics (MD) simulations would be necessary to fully understand the orientation dynamics of FLAPO in a liquid crystal. Nevertheless, their capability for ratiometric detection of small viscosity changes at the nematic-isotropic phase transition, which was also confirmed from microscopic measurements (Fig. S3-6), make flapping fluorophores promising candidates where other probes fall short. 

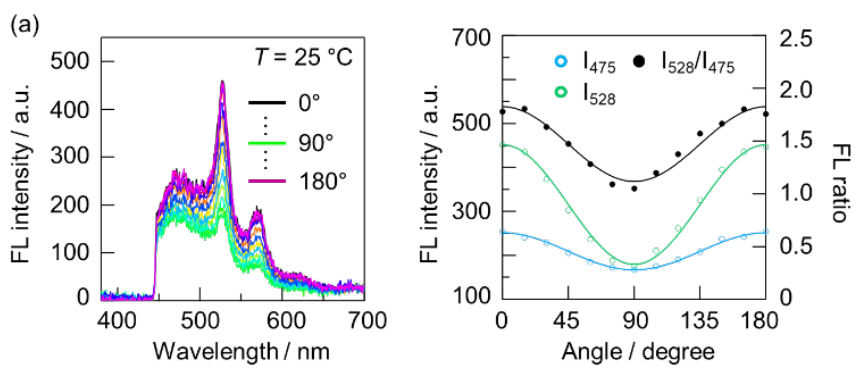

(b)

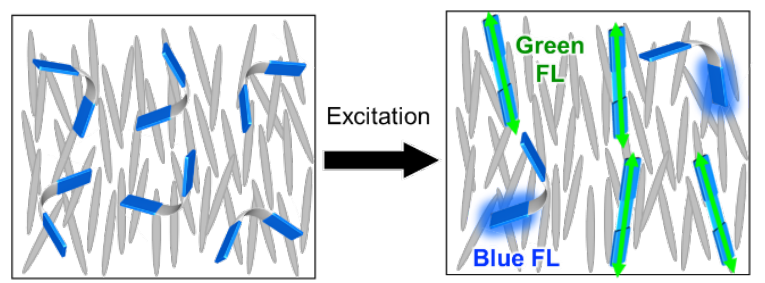

Fig. 5. (a) Analyzer-angle dependence in the FL spectra of FLAPO doped in $5 \mathrm{CB}$ at $25^{\circ} \mathrm{C}$ (nematic phase, uniaxial alignment) (left). Nonpolarized excitation: $380 \mathrm{~nm}$. The FL intensities at $475 \mathrm{~nm}$ and 528 $\mathrm{nm}$, and the FL ratio of $I_{528} / I_{475}$ plotted with relative directions to the $5 C B$ director (right). (b) Schematic representation of the anisotropic green fluorescence from the planarized excited species and the less anisotropic blue fluorescence from the V-shaped excited species.

\section{Conclusion}

Three molecular viscosity probes, a ratiometric flapping fluorophore FLAP0, a fluorogenic flapping fluorophore FLAP1, and a fluorogenic molecular motor BODIPY- $\mathrm{C}_{12}$ were doped in a nematic liquid crystal $5 \mathrm{CB}$, and their fluorescence properties were analyzed at different temperatures. As a result, only by the ratiometric fluorescence spectroscopy using FLAPO, a small discontinuous viscosity gap (corresponding to a few CP change in shear viscosity around $20 \mathrm{cP}$ ) during the nematic-to-isotropic phase transition of 5 CB was successfully detected. Moreover, planarized emissive species of FLAPO tend to be parallel to the director of $5 \mathrm{CB}$. These results provide a deeper insight into the molecular theory of the liquid crystal viscosity and will lead to real-time 2D imaging technique of local viscosity during the phase transition of liquid crystals.

\section{Acknowledgement}

This work was supported by JST PRESTO (FRONTIER) and JST FOREST Grant Numbers JPMJPR16P6 (S.S) and JPMJFR201L (S.S.), JSPS KAKENHI Grant Numbers JP21H01917 (S.S), JP19H02581 (H.Y). and JP20K21154 (H.Y.), MEXT LEADER Program (H.Y.), Toray Science Foundation (S.S.) and JSPS Research Fellowship for Young Scientists Grant Numbers JP21J22951 to R.K. and JP19J22034 to T. Y.

\section{References}

1. P-. G. de Gennes and J. Prost, The Physics of Liquid Crystals, 2nd Ed, Clarendon Press, Oxford, 1993.

2. (a) H. Chen, M. Hu, F. Peng, J. Li, Z. An and S.-T. Wu, Optical Materials Express, 2015, 5, 655; (b) S. Čopar, Ž. Kos, T. Emeršič, and U. Tkalec, Nature Commun. 2020, 11, 59.

3. (a) V. V. Beryaev, Viscosity of Nematic Liquid Crystals, Cambridge Intl. Science Pub., 2009; (b) H. Kneppe, F. Schneider and N. K. Sharma, J. Chem. Phys., 1982, 77, 3203; (c) A. G. Chmielewski, Mol. Cryst. Liq. Cryst., 1986, 132, 339; (d) S-. T. Wu and C.-S. Wu, Physical Review A, 1990, 42, 2219.

4. R. Shimada, O. Urakawa, T. Inoue and H. Watanabe, Soft Matter, 2021, 17, 6259.

5. F. Zhou, J. Shao, Y. Yang, J. Zhao, H. Guo, X. Li, S. Ji and Z. Zhang, Eur. J. Org. Chem. 2011, 4773.

6. (a) M. K. Kuimova, Phys. Chem. Chem. Phys. 2012, 14, 12671; (b) M. A. Haidekker and E. A. Theodrakis, J. Mater. Chem. C 2016, 4, 2707; (c) A. S. Klymchenko, Acc. Chem. Res., 2017, $50,366$.

7. (a) H. Itagaki, K. Horie and I. Mita, Prog. Polym. Sci., 1990, 15, 361; (b) B. Strehmel, V. Strehmel and M. Younes, J. Polym. Sci., Part B: Polym. Phys., 1999, 37, 1367; (c) M. Aoki, D. Kawaguchi, T. Ganbe, N. Sekine, K. Okamoto and K. Tanaka, Chem. Lett. 2015. 44, 659.

8. (a) R. Kotani, H. Sotome, H. Okajima, S. Yokoyama, Y. Nakaike, A. Kashiwagi, C. Mori, Y. Nakada, S. Yamaguchi, A. Osuka, A. Sakamoto, H. Miyasaka and S. Saito, J. Mater. Chem. C 2017, 5, 5248; (b) C. Yuan, S. Saito, C. Camacho, S. Irle, I. Hisaki and S. Yamaguchi, J. Am. Chem. Soc. 2013, 135, 8842; (c) W. Nakanishi, S. Saito, N. Sakamoto, A. Kashiwagi, S. Yamaguchi, H. Sakai and K. Ariga, Chem. Asian J. 2019, 14, 2869; (d) R. Kimura, H. Kuramochi, P. Liu, T. Yamakado, A. Osuka, T. Tahara and S. Saito, Angew. Chem. Int. Ed. 2020, 59, 16430; (e) R. Kimura, H. Kitakado, A. Osuka and S. Saito, Bull. Chem. Soc. Jpn. 2020, 93, 1102; (f) Y. Goto, S. Omagari, R. Sato, T. Yamakado, R. Achiwa, N. Dey, K. Suga, M. Vacha and S. Saito, J. Am. Chem. Soc. 2021, 143, 14306.

9. A. Polita, S. Toliautas, R. Žvirblis and A. Vyšiauskas, Phys. Chem. Chem. Phys., 2020, 22, 8296.

10. (a) M. Hada, S. Saito, S. Tanaka, R. Sato, M. Yoshimura, K. Mouri, K. Matsuo, S. Yamaguchi, M. Hara, Y. Hayashi, F. Röhricht, R. Herges, Y. Shigeta, K. Onda and R. J. Dwayne Miller, J. Am. Chem. Soc. 2017, 139, 15792; (b) M. Hada, D. Yamaguchi, T. Ishikawa, T. Sawa, K. Tsuruta, K. Ishikawa, S. Koshihara, Y. Hayashi and T. Kato, Nat. Commun. 2019, 10, 4159.

\section{Conflicts of interest}

There are no conflicts to declare. 


\title{
Supporting Information
}

\section{Probing a Local Viscosity Change at the Nematic-Isotropic Liquid Crystal Phase Transition by a Ratiometric Flapping Fluorophore}

\author{
Ryo Kimura, ${ }^{a}$ Hidetsugu Kitakado, ${ }^{a}$ Takuya Yamakado,${ }^{a}$ Hiroyuki Yoshida, ${ }^{* b}$ and Shohei Saito*a \\ ${ }^{a}$ Graduate School of Science, Kyoto University, Kitashirakawa Oiwake, Sakyo, Kyoto 606-8502, Japan \\ ${ }^{b}$ Graduate School of Engineering, Osaka University, 2-1 Yamadaoka, Suita, Osaka 565-0871, Japan
}

\section{Corresponding Authors}

yoshida@eei.eng.osaka-u.ac.jp

s_saito@kuchem.kyoto-u.ac.jp

\section{Contents}

1. General information S2

2. Photophysical, rheological, and thermal analyses S3-S12

3. Microscopic measurements S13-S15

4. Density functional theory (DFT) calculations S16-S20

5. Supporting references S2 1 


\section{General information}

\section{Synthesis}

All reagents and solvents were of commercial grade and were used without further purification unless otherwise noted. Benzonitrile $(\mathrm{PhCN})$ was distilled before optical measurements. FLAPO $^{[\mathrm{S} 1]}$, FLAP1 $^{[\mathrm{S} 2]}$, Wing1 ${ }^{[\mathrm{S} 2]}$, and BODIPY- $\mathrm{C}_{12}{ }^{\left[{ }^{[3}\right]}$ were synthesized according to the reported methods.

\section{Measurements}

All optical measurements were performed under air-saturated condition. In Chapter 2, excitation light and emissions were non-polarized. UV-visible absorption spectra were recorded on a Shimadzu UV-3600 spectrometer. Steady-state fluorescence and excitation spectra were recorded on a JASCO FP-8500 spectrofluorometer. Absolute fluorescence quantum yields were determined by an integrating sphere system on a HAMAMATSU C9920-02S apparatus. Fluorescence lifetimes were measured on a compact fluorescence lifetime spectrometer Hamamatsu Photonics QuantaurusTau C11367. Optical measurements were conducted using a 1-cm square quartz cell in $\mathrm{PhCN}$, and 1-mm quartz cell in 5CB. Measurements of temperature-dependent FL spectra and FL lifetimes were conducted on UNISOKU CoolSpeK connected with a JASCO FP-8500 or a Hamamatsu Photonics QuantaurusTau C11367. Shear viscosity of 5CB was measured on an Anton Paar MCR702 rheometer. Differential scanning calorimetry (DSC) was recorded on a Hitachi High-Tech TA7000.

In Chapter 3, the optical set-up and measurement conditions were shown in the following Figures. 


\section{Photophysical, rheological, and thermal analyses}

(a)

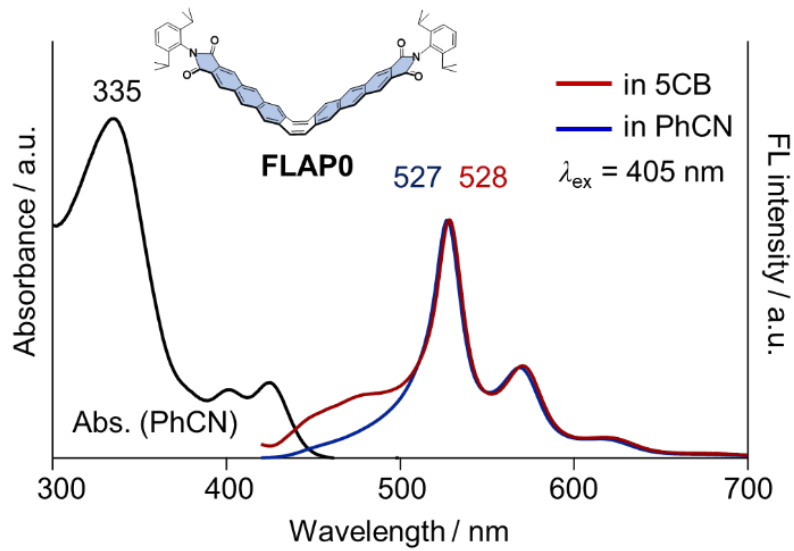

(b)

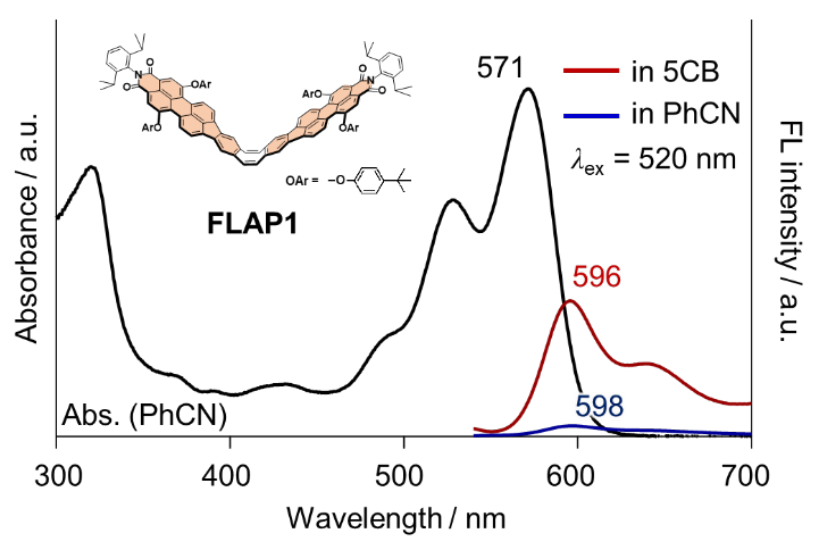

(d)

(c)

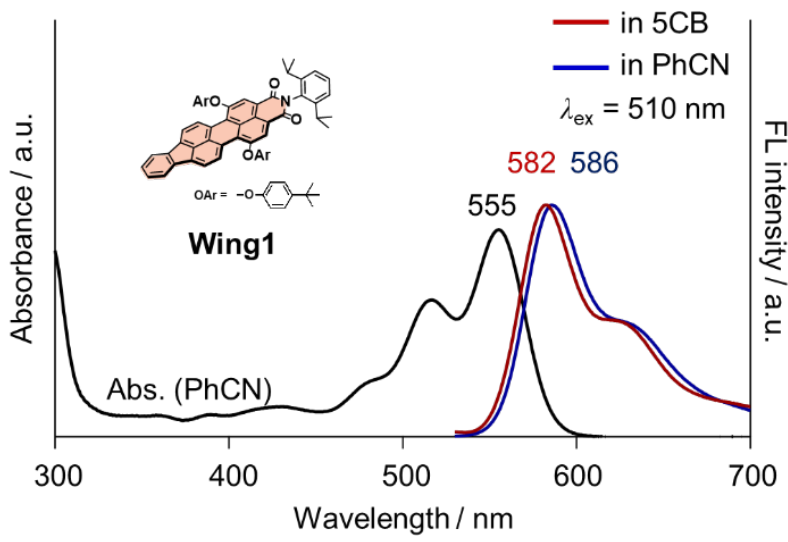

Figure S2-1. UV-visible absorption and FL spectra of (a) FLAP0, (b) FLAP1, (c) Wing1, and (d) BODIPY-C 12 in PhCN and 5CB. Excitation wavelengths: $405 \mathrm{~nm}$ for FLAP0, $520 \mathrm{~nm}$ for FLAP1, $510 \mathrm{~nm}$ for Wing1, and $460 \mathrm{~nm}$ for BODIPY-C 12 . 

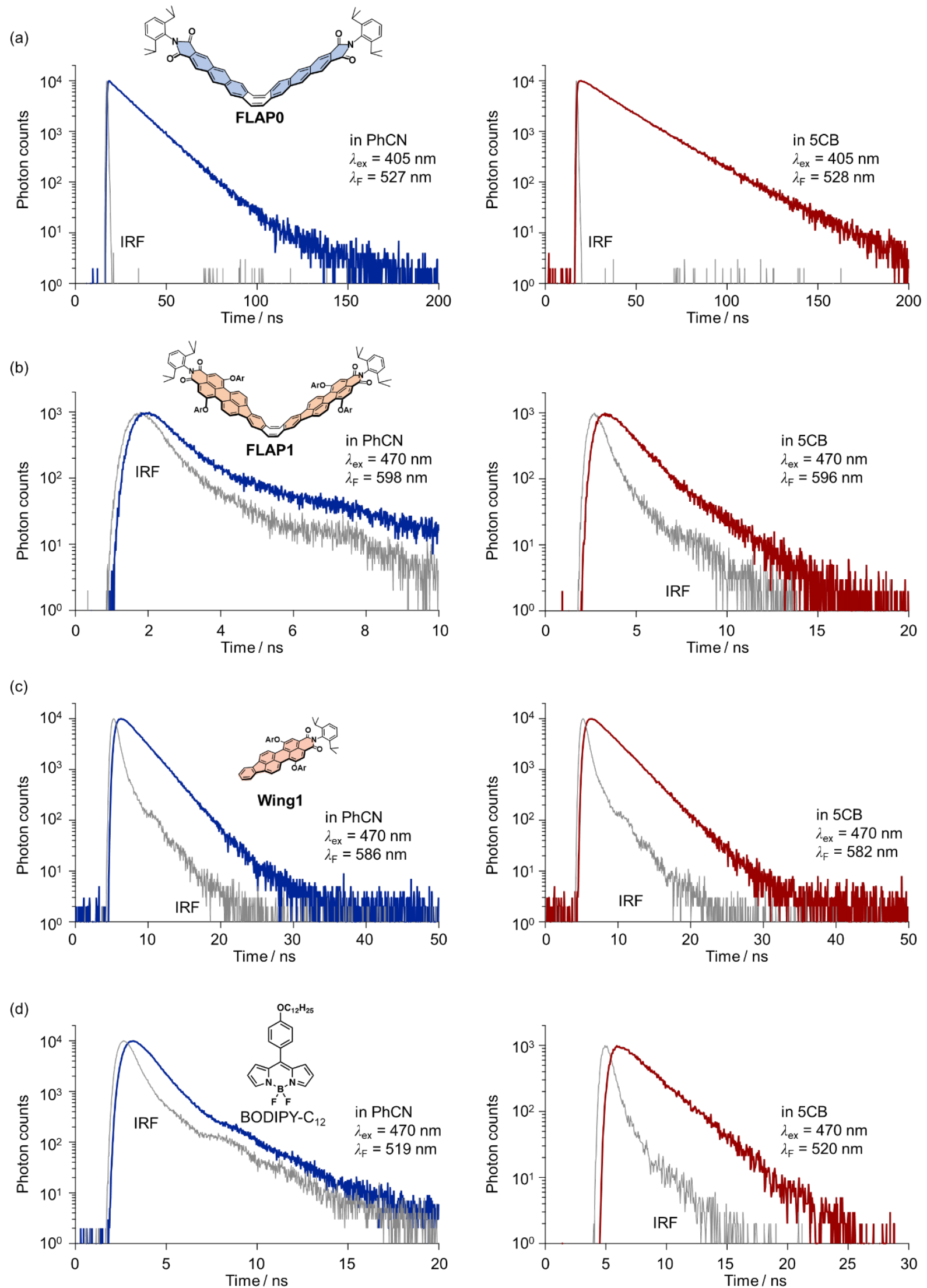

Figure S2-2. FL decay profiles of (a) FLAP0, (b) FLAP1, (c) Wing1, and (d) BODIPY-C 12 in PhCN (left) and 5CB (right). Excitation and fluorescence wavelengths are shown in each panel. 
Table S2-1. FL quantum yield $\Phi_{\mathrm{F}}$ and FL lifetime $\tau_{\mathrm{F}}$ of FLAP0, FLAP1, Wing1, and BODIPY-C 12 in PhCN and $5 \mathrm{CB}$.

\begin{tabular}{cccccccc}
\hline Compounds & Solvents & $\Phi_{\mathrm{F}}{ }^{[\mathrm{a}]}$ & $\tau_{\mathrm{F} 1}$ & $\tau_{\mathrm{F} 2}$ & $A_{1}$ & $A_{2}$ & $\chi^{2}$ \\
\hline \multirow{2}{*}{ FLAP0 } & $\mathrm{PhCN}$ & 0.44 & $0.13 \mathrm{~ns}^{[\mathrm{b}]}$ & $13 \mathrm{~ns}$ & $-1840^{[\mathrm{b}]}$ & 2270 & 1.22 \\
& $5 \mathrm{CB}$ & 0.48 & $0.62 \mathrm{~ns}^{[\mathrm{b}]}$ & $20 \mathrm{~ns}$ & $-1290^{[\mathrm{b}]}$ & 2440 & 1.68 \\
\hline FLAP1 & $\mathrm{PhCN}$ & 0.008 & $0.16 \mathrm{~ns}^{[\mathrm{b}]}$ & $2.8 \mathrm{~ns}$ & $64^{[\mathrm{b}]}$ & 1.0 & 1.25 \\
& $5 \mathrm{CB}$ & 0.11 & $1.1 \mathrm{~ns}$ & & & & 1.22 \\
\hline Wing1 & $\mathrm{PhCN}$ & 0.37 & $2.2 \mathrm{~ns}$ & & & & 1.18 \\
& $5 \mathrm{CB}$ & 0.46 & $2.6 \mathrm{~ns}$ & & & & 1.30 \\
\hline BODIPY-C 12 & $\mathrm{PhCN}$ & 0.056 & $0.62 \mathrm{~ns}$ & & & & 1.42 \\
& $5 \mathrm{CB}$ & 0.26 & $2.2 \mathrm{~ns}$ & & & & 1.29 \\
\hline
\end{tabular}

[a] Excitation wavelengths for the determination of $\Phi_{\mathrm{F}}: \lambda_{\mathrm{ex}}=405 \mathrm{~nm}$ (FLAP0), $\lambda_{\mathrm{ex}}=520 \mathrm{~nm}$ (FLAP1), $\lambda_{\mathrm{ex}}=510$ $\mathrm{nm}$ (Wing1), and $\lambda_{\mathrm{ex}}=460 \mathrm{~nm}$ (BODIPY-C $\mathrm{C}_{12}$ ).

[b] FL lifetime was fitted with $f(t)=A_{1} \exp \left(-t / \tau_{1}\right)+A_{2} \exp \left(-t / \tau_{2}\right)$. Short-lived components $\left(\tau_{1}<1 \mathrm{~ns}\right)$ of FLAP0 obtained as negative $A_{1}$ values would originate from planarization dynamics in the excited state. ${ }^{[\mathrm{S} 2]}$ 

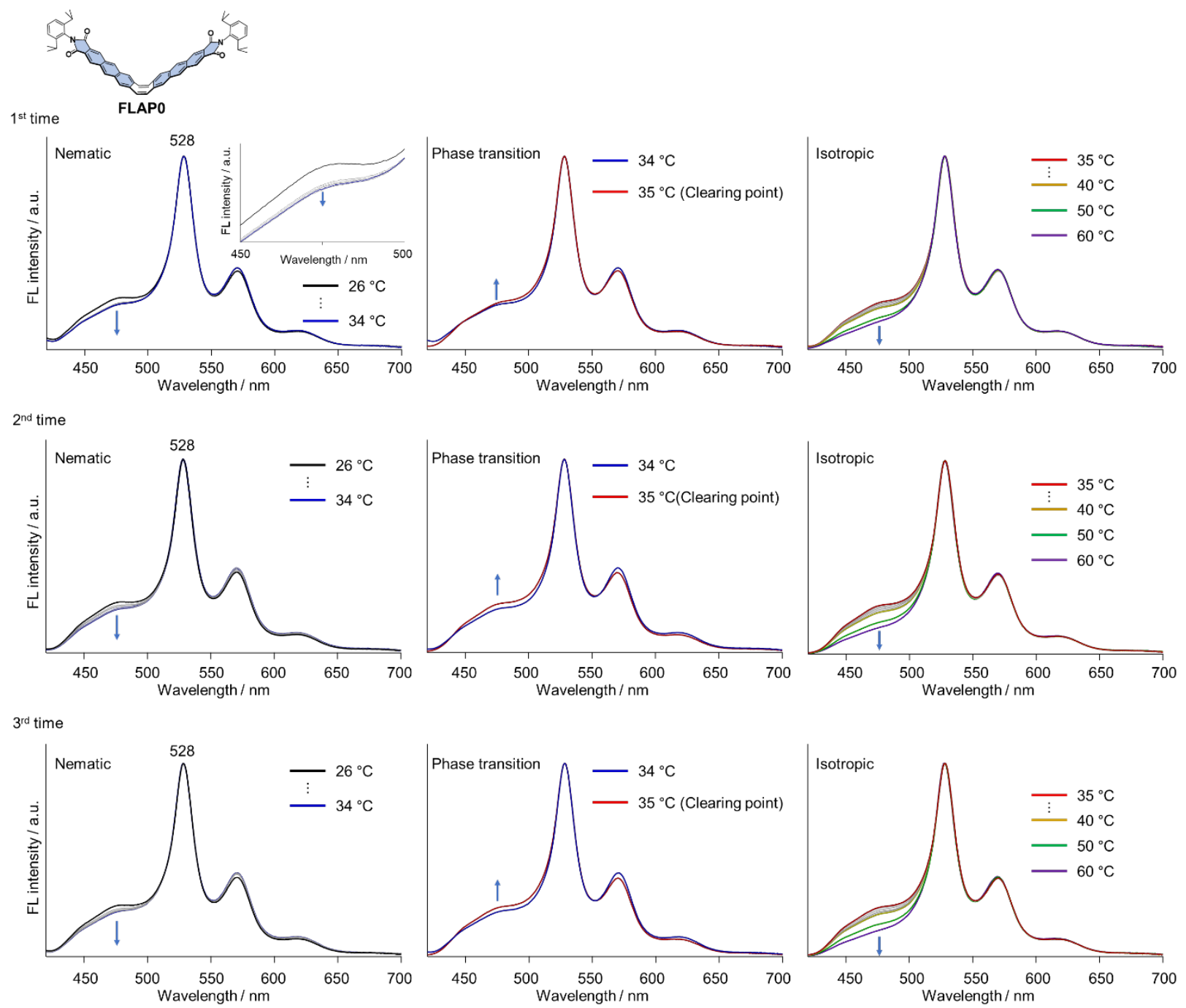

Figure S2-3. Temperature-dependent FL spectra of FLAP0 in 5CB $\left(\lambda_{\mathrm{ex}}=405 \mathrm{~nm}\right)$. The measurements were performed three times.

Table S2-2. Temperature-dependent FL ratio of FLAP0 in 5CB $\left(\lambda_{\mathrm{ex}}=405 \mathrm{~nm}\right)$ for the three measurements.

\begin{tabular}{ccccc}
\hline \multirow{2}{*}{ Temperature $/{ }^{\circ} \mathrm{C}$} & \multicolumn{3}{c}{ FL ratio $\left(\boldsymbol{I}_{\mathbf{5 2 8}} / \boldsymbol{I}_{\mathbf{4 7 5}}\right)$} \\
\cline { 2 - 5 } & 26 & $1^{\text {st }}$ & $2^{\text {nd }}$ & $3^{\text {rd }}$ \\
\hline \multirow{4}{*}{ Nematic } & 3.78 & 3.86 & 3.81 \\
& 30 & 4.22 & 4.11 & 4.10 \\
& 31 & 4.26 & 4.22 & 4.23 \\
& 32 & 4.29 & 4.45 & 4.28 \\
& 33 & 4.36 & 4.44 & 4.30 \\
Clearing point & 34 & 4.34 & 4.47 & 4.34 \\
& 35 & 4.16 & 4.01 & 3.96 \\
& 36 & 4.25 & 4.11 & 4.03 \\
Isotropic & 37 & 4.35 & 4.23 & 4.18 \\
& 38 & 4.50 & 4.36 & 4.34 \\
& 39 & 4.62 & 4.53 & 4.47 \\
& 40 & 4.71 & 4.68 & 4.61 \\
& 50 & 6.14 & 6.15 & 6.03 \\
& 60 & 7.00 & 7.37 & 7.45 \\
\hline
\end{tabular}


(a)

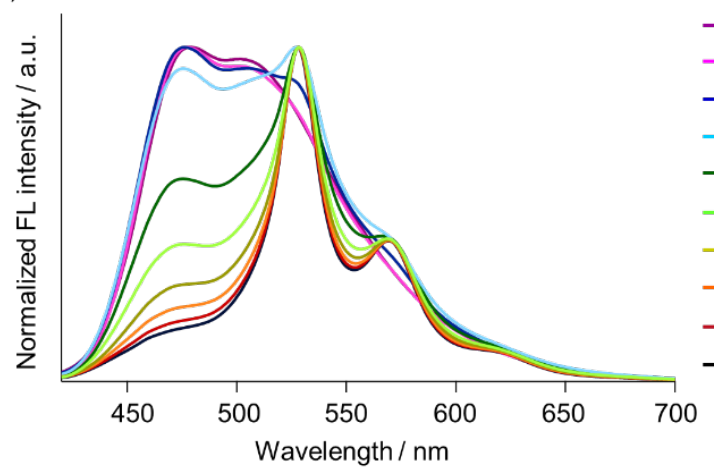

DMSO / Glycerol $\eta / \mathrm{cP}$

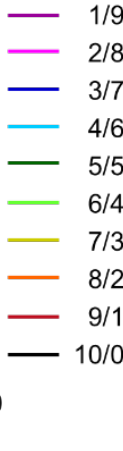

(b)

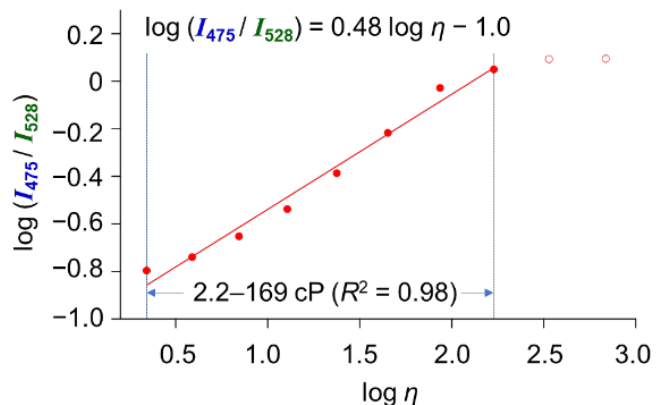

(c)

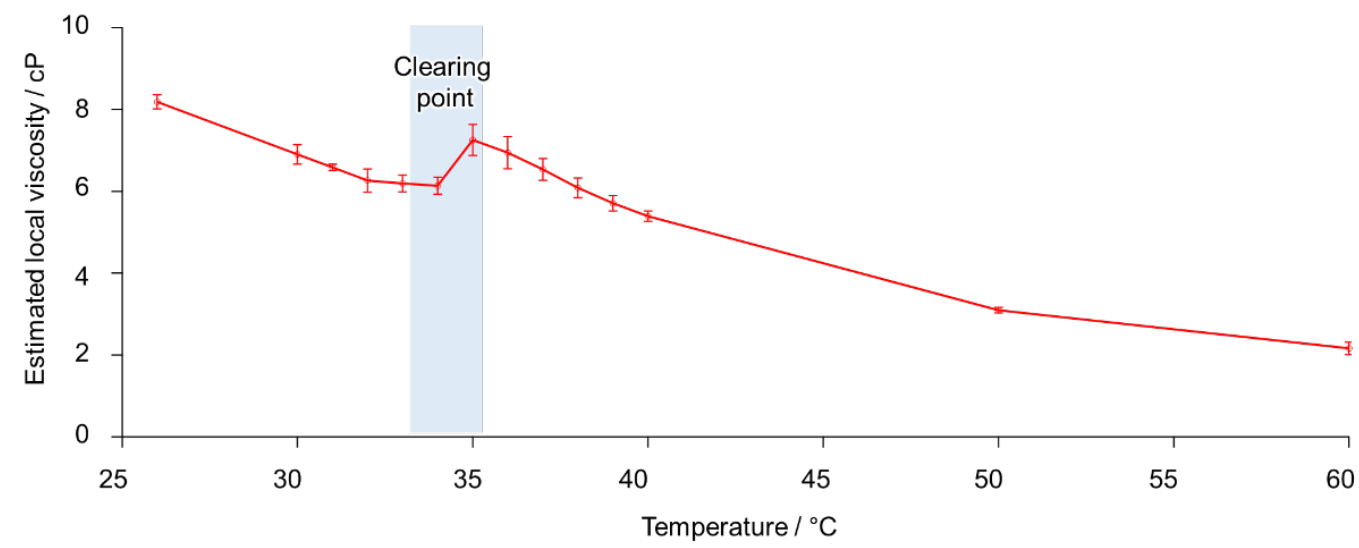

Figure S2-4. (a) Viscosity-dependent FL spectra of FLAP0 in mixed solvents of DMSO/glycerol (v/v). Excitation by non-polarized light $\left(\lambda_{\mathrm{ex}}=405 \mathrm{~nm}\right)$. (b) The corresponding Förster-Hoffman plot between $2.2 \mathrm{cP}$ to $169 \mathrm{cP}$. (c) Local viscosity of $5 \mathrm{CB}$ at each temperature estimated from the Förster-Hoffman calibration of FLAP0. Measurements were performed 3 times to display sample standard deviation. The local viscosity of 5CB was formally estimated as $6.1 \pm 0.2 \mathrm{cP}$ at $34^{\circ} \mathrm{C}$ and $7.3 \pm 0.4 \mathrm{cP}$ at $35^{\circ} \mathrm{C}$, although the anisotropy of the FL ratio (See Chapter 3 ) was not considered in these values.

Note: The previously reported Förster-Hoffman plot ${ }^{[\mathrm{S} 4]}$ was corrected as a double logarithmic graph from the same dual fluorescence spectra. 


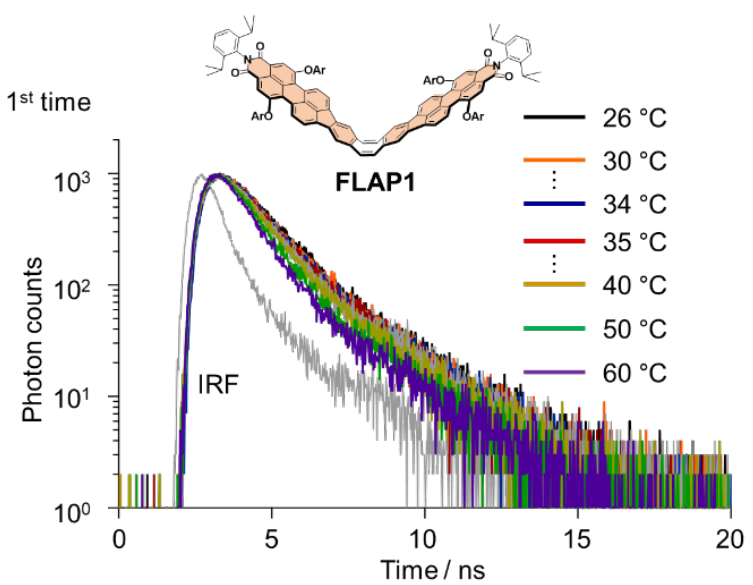

\begin{tabular}{|c|c|c|c|}
\hline \multicolumn{2}{|c|}{ Temperature $/{ }^{\circ} \mathrm{C}$} & $\tau_{\mathrm{F}}$ & $\chi^{2}$ \\
\hline \multirow{6}{*}{ Nematic } & 26 & $1.1 \mathrm{~ns}$ & 1.22 \\
\hline & 30 & $1.0 \mathrm{~ns}$ & 1.49 \\
\hline & 31 & $0.97 \mathrm{~ns}$ & 1.33 \\
\hline & 32 & $0.94 \mathrm{~ns}$ & 1.45 \\
\hline & 33 & $0.93 \mathrm{~ns}$ & 1.48 \\
\hline & 34 & $0.94 \mathrm{~ns}$ & 1.44 \\
\hline Clearing point & 35 & $0.93 \mathrm{~ns}$ & 1.35 \\
\hline \multirow{7}{*}{ Isotropic } & 36 & $0.91 \mathrm{~ns}$ & 1.37 \\
\hline & 37 & $0.88 \mathrm{~ns}$ & 1.20 \\
\hline & 38 & $0.88 \mathrm{~ns}$ & 1.32 \\
\hline & 39 & $0.85 \mathrm{~ns}$ & 1.21 \\
\hline & 40 & $0.86 \mathrm{~ns}$ & 1.35 \\
\hline & 50 & $0.71 \mathrm{~ns}$ & 1.31 \\
\hline & 60 & $0.61 \mathrm{~ns}$ & 1.32 \\
\hline
\end{tabular}

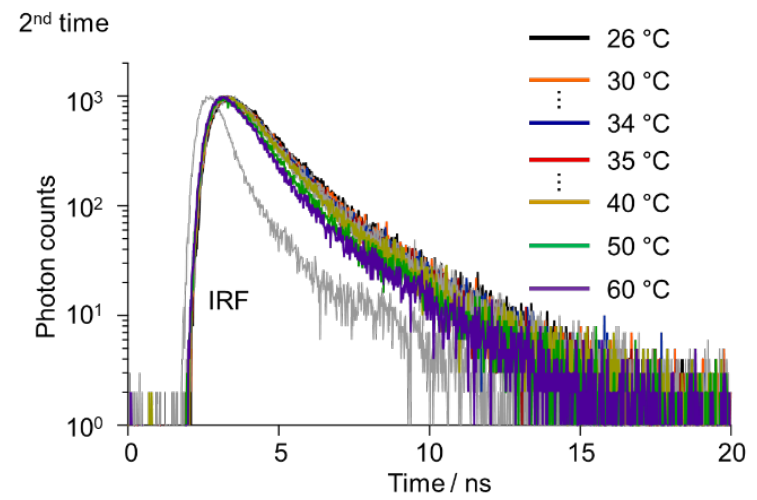

\begin{tabular}{|c|c|c|c|}
\hline \multicolumn{2}{|c|}{ Temperature $/{ }^{\circ} \mathrm{C}$} & \multirow{2}{*}{$\begin{array}{c}\tau_{\mathrm{F}} \\
1.1 \mathrm{~ns}\end{array}$} & \multirow{2}{*}{$\begin{array}{c}\frac{\chi^{2}}{1.40} \\
\end{array}$} \\
\hline \multirow{6}{*}{ Nematic } & 26 & & \\
\hline & 30 & $1.0 \mathrm{~ns}$ & 1.43 \\
\hline & 31 & $0.99 \mathrm{~ns}$ & 1.43 \\
\hline & 32 & $0.97 \mathrm{~ns}$ & 1.53 \\
\hline & 33 & $0.97 \mathrm{~ns}$ & 1.40 \\
\hline & 34 & $0.95 \mathrm{~ns}$ & 1.52 \\
\hline Clearing point & 35 & $0.96 \mathrm{~ns}$ & 1.35 \\
\hline \multirow{7}{*}{ Isotropic } & 36 & $0.95 \mathrm{~ns}$ & 1.43 \\
\hline & 37 & $0.92 \mathrm{~ns}$ & 1.39 \\
\hline & 38 & $0.93 \mathrm{~ns}$ & 1.33 \\
\hline & 39 & $0.90 \mathrm{~ns}$ & 1.48 \\
\hline & 40 & $0.90 \mathrm{~ns}$ & 1.35 \\
\hline & 50 & $0.76 \mathrm{~ns}$ & 1.38 \\
\hline & 60 & $0.65 \mathrm{~ns}$ & 1.43 \\
\hline
\end{tabular}

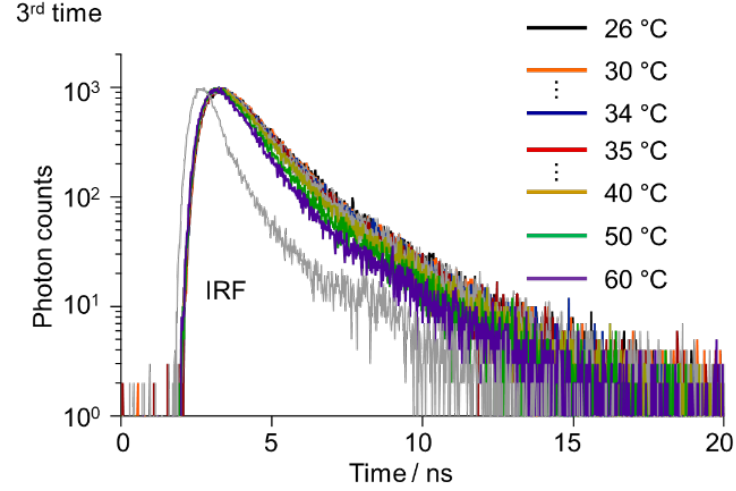

\begin{tabular}{|c|c|c|c|}
\hline \multicolumn{2}{|c|}{ Temperature $/{ }^{\circ} \mathrm{C}$} & \multirow{2}{*}{$\begin{array}{c}\tau_{\mathrm{F}} \\
1.1 \mathrm{~ns}\end{array}$} & \multirow{2}{*}{$\begin{array}{c}\chi^{2} \\
1.37\end{array}$} \\
\hline \multirow{6}{*}{ Nematic } & 26 & & \\
\hline & 30 & $0.99 \mathrm{~ns}$ & 1.30 \\
\hline & 31 & $0.99 \mathrm{~ns}$ & 1.42 \\
\hline & 32 & $0.98 \mathrm{~ns}$ & 1.54 \\
\hline & 33 & $0.96 \mathrm{~ns}$ & 1.42 \\
\hline & 34 & $0.94 \mathrm{~ns}$ & 1.52 \\
\hline Clearing point & 35 & $0.95 \mathrm{~ns}$ & 1.42 \\
\hline \multirow{7}{*}{ Isotropic } & 36 & $0.94 \mathrm{~ns}$ & 1.47 \\
\hline & 37 & $0.92 \mathrm{~ns}$ & 1.50 \\
\hline & 38 & $0.90 \mathrm{~ns}$ & 1.48 \\
\hline & 39 & $0.88 \mathrm{~ns}$ & 1.39 \\
\hline & 40 & $0.86 \mathrm{~ns}$ & 1.33 \\
\hline & 50 & $0.75 \mathrm{~ns}$ & 1.52 \\
\hline & 60 & $0.64 \mathrm{~ns}$ & 1.36 \\
\hline
\end{tabular}

Figure S2-5. Temperature-dependent FL decay profiles and FL lifetimes of FLAP1 in 5CB $\left(\lambda_{\mathrm{ex}}=470 \mathrm{~nm}\right.$ and $\lambda_{\mathrm{F}}=$ $596 \mathrm{~nm}$ ) for three measurements. 


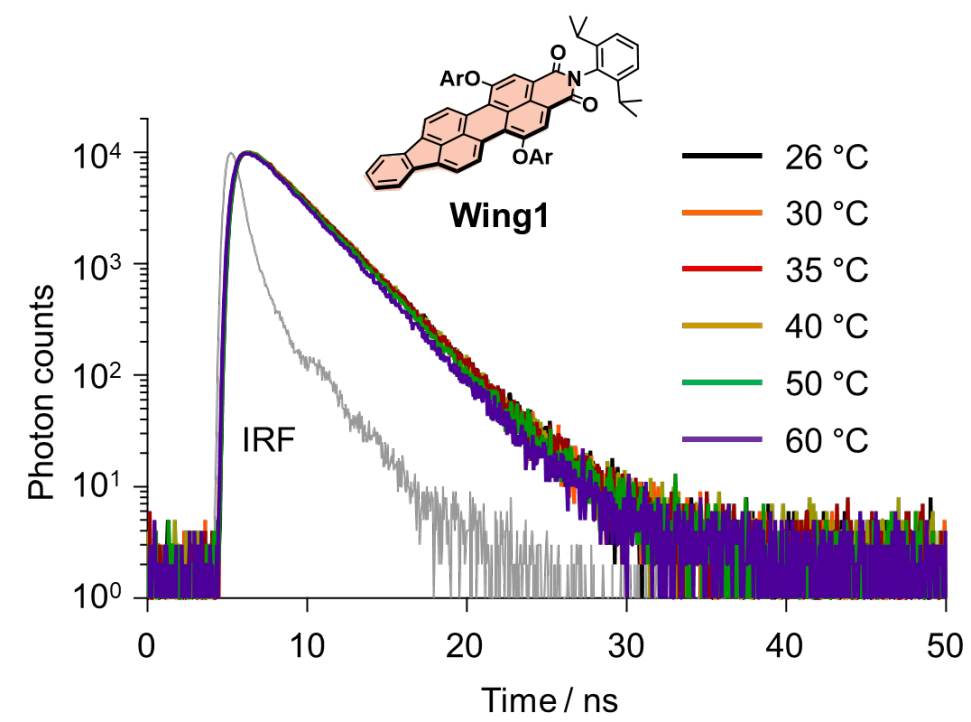

\begin{tabular}{|c|c|c|c|}
\hline \multicolumn{2}{|c|}{ Temperature $/{ }^{\circ} \mathrm{C}$} & $\tau_{\mathrm{F}}$ & $\chi^{2}$ \\
\hline \multirow{2}{*}{ Nematic } & 26 & $2.6 \mathrm{~ns}$ & 1.30 \\
\hline & 30 & $2.6 \mathrm{~ns}$ & 1.39 \\
\hline $\begin{array}{c}\text { Clearing } \\
\text { point }\end{array}$ & 35 & $2.6 \mathrm{~ns}$ & 1.30 \\
\hline \multirow{3}{*}{ Isotropic } & 40 & $2.6 \mathrm{~ns}$ & 1.29 \\
\hline & 50 & $2.5 \mathrm{~ns}$ & 1.40 \\
\hline & 60 & $2.4 \mathrm{~ns}$ & 1.65 \\
\hline
\end{tabular}

Figure S2-6. No temperature dependence of FL decay profiles and FL lifetimes of Wing1 in 5CB $\left(\lambda_{\mathrm{ex}}=470 \mathrm{~nm}\right.$ and $\left.\lambda_{\mathrm{F}}=582 \mathrm{~nm}\right)$. 


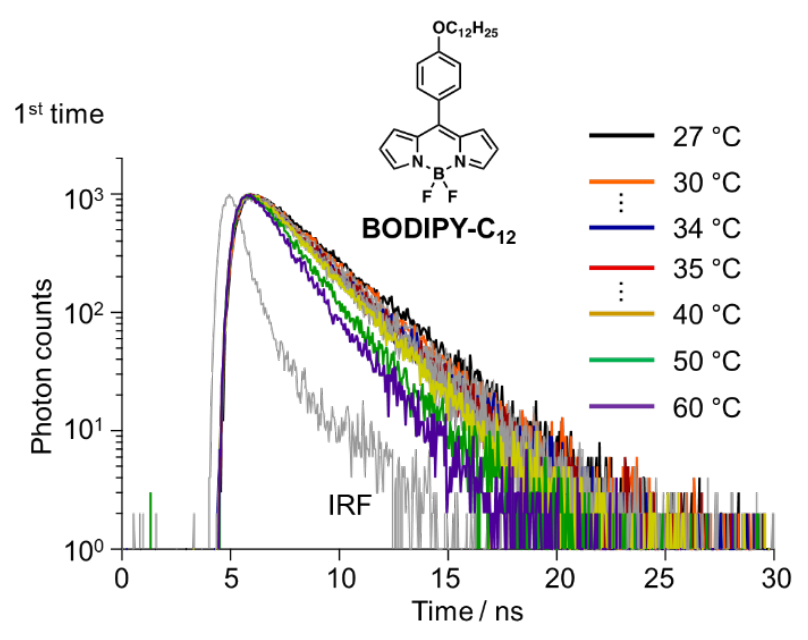

\begin{tabular}{|c|c|c|c|}
\hline \multicolumn{2}{|c|}{ Temperature $/{ }^{\circ} \mathrm{C}$} & \multirow{2}{*}{$\begin{array}{c}\tau_{\mathrm{F}} \\
2.3 \mathrm{~ns}\end{array}$} & \multirow{2}{*}{$\begin{array}{c}\chi^{2} \\
1.11\end{array}$} \\
\hline \multirow{6}{*}{ Nematic } & 27 & & \\
\hline & 30 & $2.1 \mathrm{~ns}$ & 1.00 \\
\hline & 31 & $2.0 \mathrm{~ns}$ & 1.15 \\
\hline & 32 & $2.0 \mathrm{~ns}$ & 1.28 \\
\hline & 33 & $2.0 \mathrm{~ns}$ & 1.26 \\
\hline & 34 & $1.9 \mathrm{~ns}$ & 1.33 \\
\hline Clearing point & 35 & $1.9 \mathrm{~ns}$ & 1.63 \\
\hline \multirow{7}{*}{ Isotropic } & 36 & $1.9 \mathrm{~ns}$ & 1.52 \\
\hline & 37 & $1.8 \mathrm{~ns}$ & 1.49 \\
\hline & 38 & $1.8 \mathrm{~ns}$ & 1.35 \\
\hline & 39 & $1.8 \mathrm{~ns}$ & 1.37 \\
\hline & 40 & $1.8 \mathrm{~ns}$ & 1.35 \\
\hline & 50 & $1.4 \mathrm{~ns}$ & 1.27 \\
\hline & 60 & $1.1 \mathrm{~ns}$ & 1.29 \\
\hline \multicolumn{2}{|c|}{ Temperature $/{ }^{\circ} \mathrm{C}$} & $\tau_{\mathrm{F}}$ & $\chi^{2}$ \\
\hline \multirow{6}{*}{ Nematic } & 27 & $2.2 \mathrm{~ns}$ & 1.10 \\
\hline & 30 & $2.1 \mathrm{~ns}$ & 1.46 \\
\hline & 31 & $2.0 \mathrm{~ns}$ & 1.10 \\
\hline & 32 & $2.0 \mathrm{~ns}$ & 1.39 \\
\hline & 33 & $1.9 \mathrm{~ns}$ & 1.24 \\
\hline & 34 & $2.0 \mathrm{~ns}$ & 1.16 \\
\hline Clearing point & 35 & $1.9 \mathrm{~ns}$ & 1.30 \\
\hline \multirow{7}{*}{ Isotropic } & 36 & $1.9 \mathrm{~ns}$ & 1.29 \\
\hline & 37 & $1.8 \mathrm{~ns}$ & 1.23 \\
\hline & 38 & $1.8 \mathrm{~ns}$ & 1.01 \\
\hline & 39 & $1.7 \mathrm{~ns}$ & 1.30 \\
\hline & 40 & $1.8 \mathrm{~ns}$ & 1.44 \\
\hline & 50 & $1.4 \mathrm{~ns}$ & 1.19 \\
\hline & 60 & $1.1 \mathrm{~ns}$ & 1.07 \\
\hline
\end{tabular}

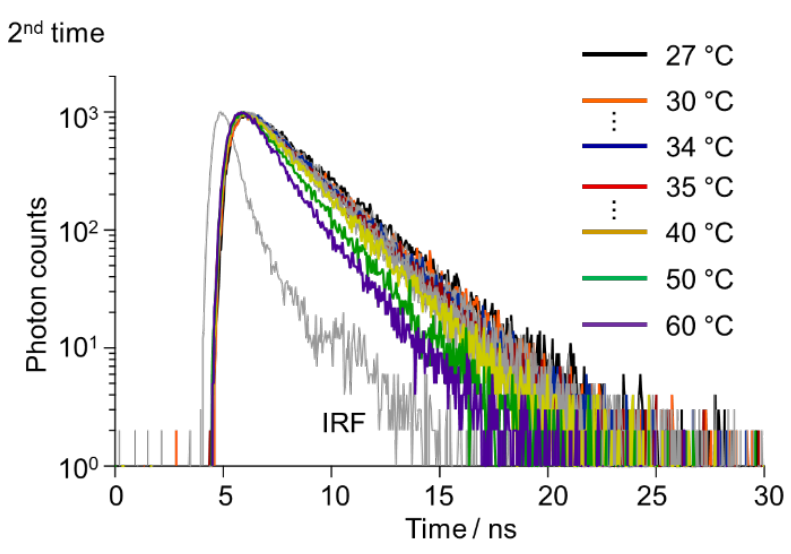

\begin{tabular}{|c|c|c|c|}
\hline \multicolumn{2}{|c|}{ Temperature $/{ }^{\circ} \mathrm{C}$} & \multirow{2}{*}{$\begin{array}{c}\tau_{\mathrm{F}} \\
2.2 \mathrm{~ns}\end{array}$} & \multirow{2}{*}{$\begin{array}{c}\chi^{2} \\
1.22\end{array}$} \\
\hline \multirow{6}{*}{ Nematic } & 27 & & \\
\hline & 30 & $2.1 \mathrm{~ns}$ & 1.34 \\
\hline & 31 & $2.0 \mathrm{~ns}$ & 1.40 \\
\hline & 32 & $2.0 \mathrm{~ns}$ & 1.16 \\
\hline & 33 & $2.0 \mathrm{~ns}$ & 1.30 \\
\hline & 34 & $1.9 \mathrm{~ns}$ & 1.39 \\
\hline Clearing point & 35 & $1.9 \mathrm{~ns}$ & 1.19 \\
\hline \multirow{7}{*}{ Isotropic } & 36 & $1.9 \mathrm{~ns}$ & 1.29 \\
\hline & 37 & $1.8 \mathrm{~ns}$ & 1.17 \\
\hline & 38 & $1.8 \mathrm{~ns}$ & 1.35 \\
\hline & 39 & $1.7 \mathrm{~ns}$ & 1.34 \\
\hline & 40 & $1.7 \mathrm{~ns}$ & 1.43 \\
\hline & 50 & $1.4 \mathrm{~ns}$ & 1.34 \\
\hline & 60 & $1.1 \mathrm{~ns}$ & 1.07 \\
\hline
\end{tabular}

Figure S2-7. Temperature-dependent FL decay profiles and FL lifetimes of BODIPY- $\mathrm{C}_{12}$ in $5 \mathrm{CB}\left(\lambda_{\mathrm{ex}}=470 \mathrm{~nm}\right.$ and $\lambda_{\mathrm{F}}=520 \mathrm{~nm}$ ) for three measurements. 
(a)

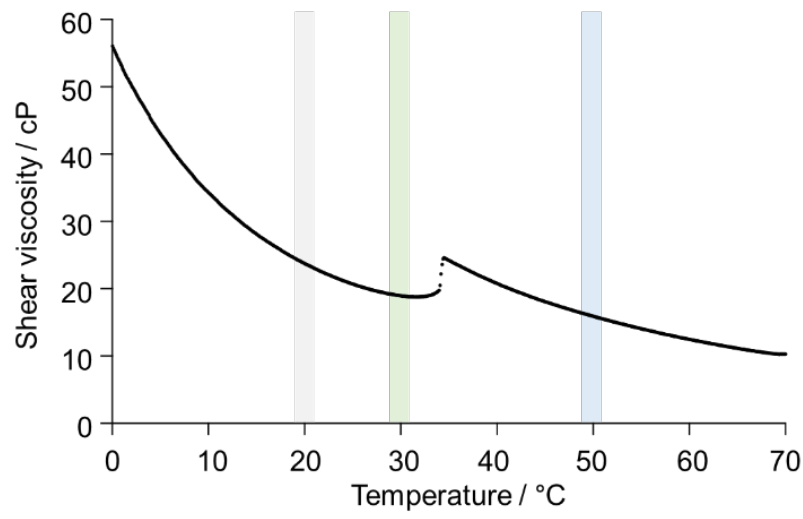

(b)

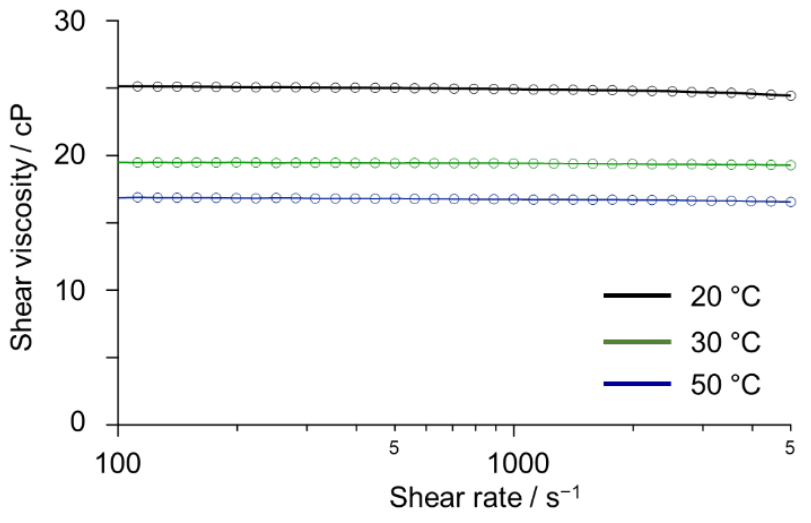

Figure S2-8. (a) Shear viscosity of $5 \mathrm{CB}$ measured by a rheometer (Shear rate: $500 \mathrm{~s}^{-1}$, cooling rate: $6^{\circ} \mathrm{C} \mathrm{min}{ }^{-1}$ ). (b) Shear rate dependence of the shear viscosity of $5 \mathrm{CB}$ at each temperature (Shear rate: 100 to $5000 \mathrm{~s}^{-1}$ ).

(a)

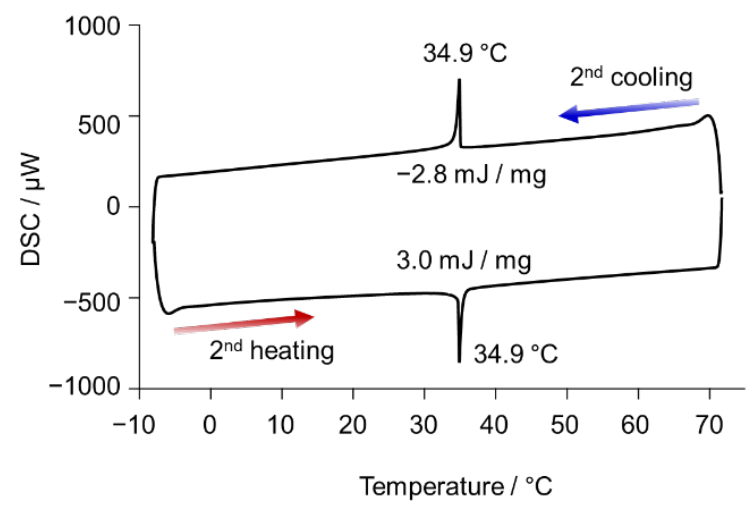

(c)

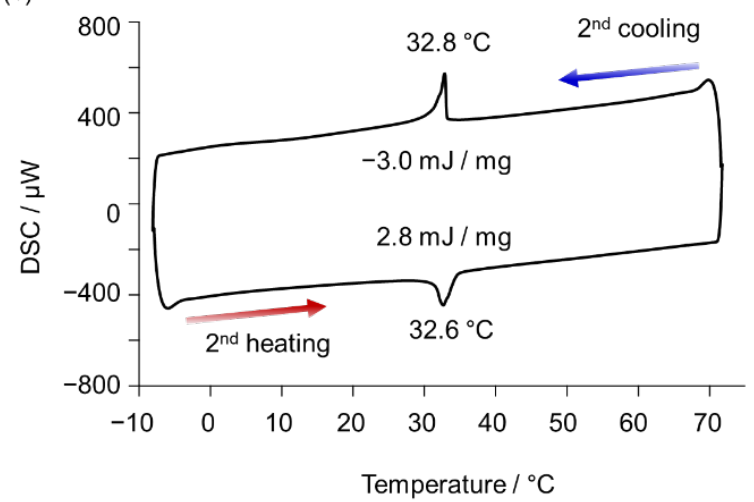

(b)

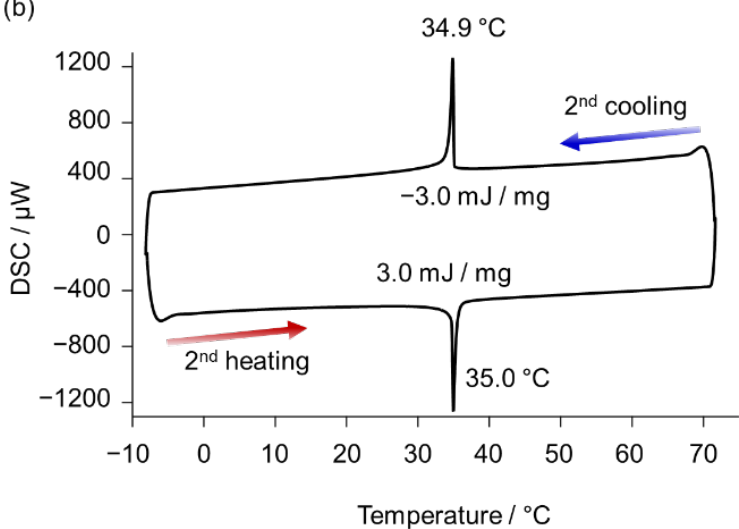

Figure S2-9. DSC analysis of (a) pure 5CB, (b) 5CB doped with FLAP0 (0.01 wt\%), and (c) 5CB doped with FLAP0 $(1 \mathrm{wt} \%)$. 
Differential scanning calorimetry (DSC) measurements were conducted under $\mathrm{N}_{2}$ atmosphere at a flow speed of 30 $\mathrm{mL} \mathrm{min}^{-1}$. Heating and cooling processes were shown in Figure S2-10. Each sample was placed in an aluminum pan and covered with an aluminum cover, which was pressed with a pressing tool. A vacant pan and a cover, which was also pressed, was used as a reference sample.

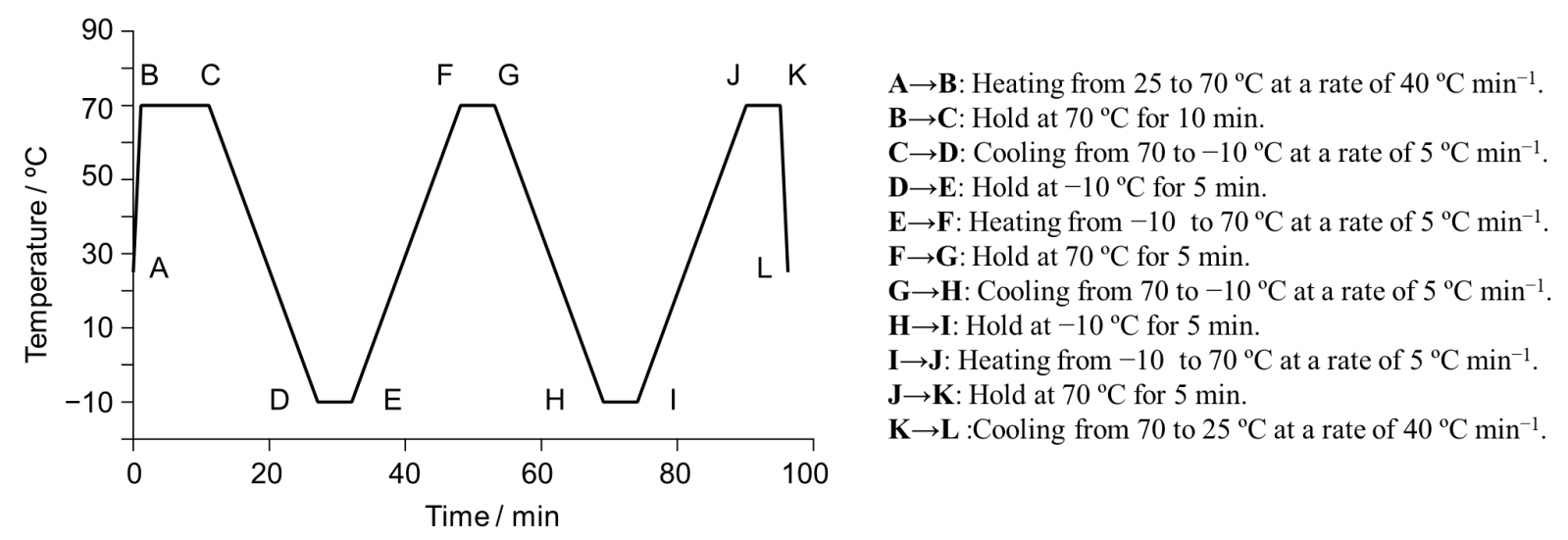

Figure S2-10. Heating and cooling processes of the DSC measurements. 


\section{Microscopic measurements}

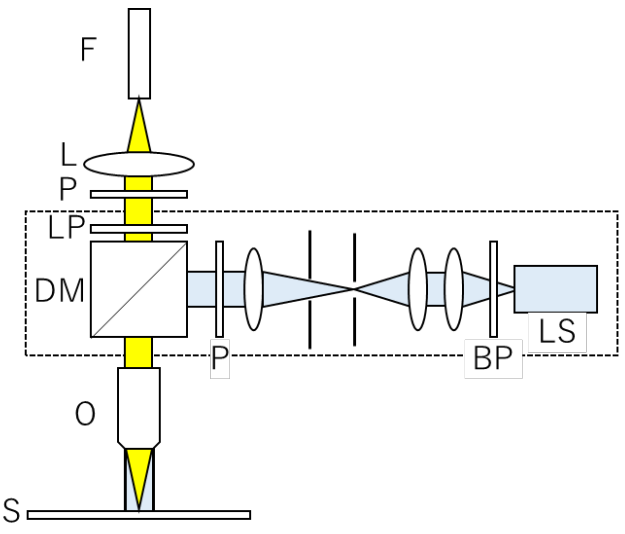

\begin{tabular}{ll}
\hline F:Fiber & BP: Band-pass filter \\
L: Lens & LS: Light-source (LED) \\
P: Polarizer & O: Objective \\
LP: Long-pass filter & S: Sample
\end{tabular}

DM: Dichroic mirror

- Light Source: Thorlabs M385L2

- Bandpass filter : Nikon Bandpass 330-380

- Dichroic mirror : Semrock Di-405-25x36

- Longpass filter : Edmund OD4.0 Longpass $450 \mathrm{~nm}$

- UV Power: $80 \mu \mathrm{W}$, spot size: $\sim 340 \mu \mathrm{m}\left(23 \mathrm{~mW} / \mathrm{cm}^{2}\right)$

Figure S3-1. Experimental setup and conditions of microscopic measurements. The polarizer in the detection path was inserted or removed as necessary. Measurements were made with typical illumination intensities of $\sim 80 \mu \mathrm{W}$ over an illumination spot of $\sim 340 \mu \mathrm{m}$ (corresponding to $\sim 20 \mathrm{~mW} / \mathrm{cm}^{2}$ ) and no photodegradation was observed during the measurements. For the analysis of the FL intensities at specified wavelengths, the intensities were extracted after applying binomial smoothing of 5 passes on the acquired spectra (performed using Igor Pro Software).
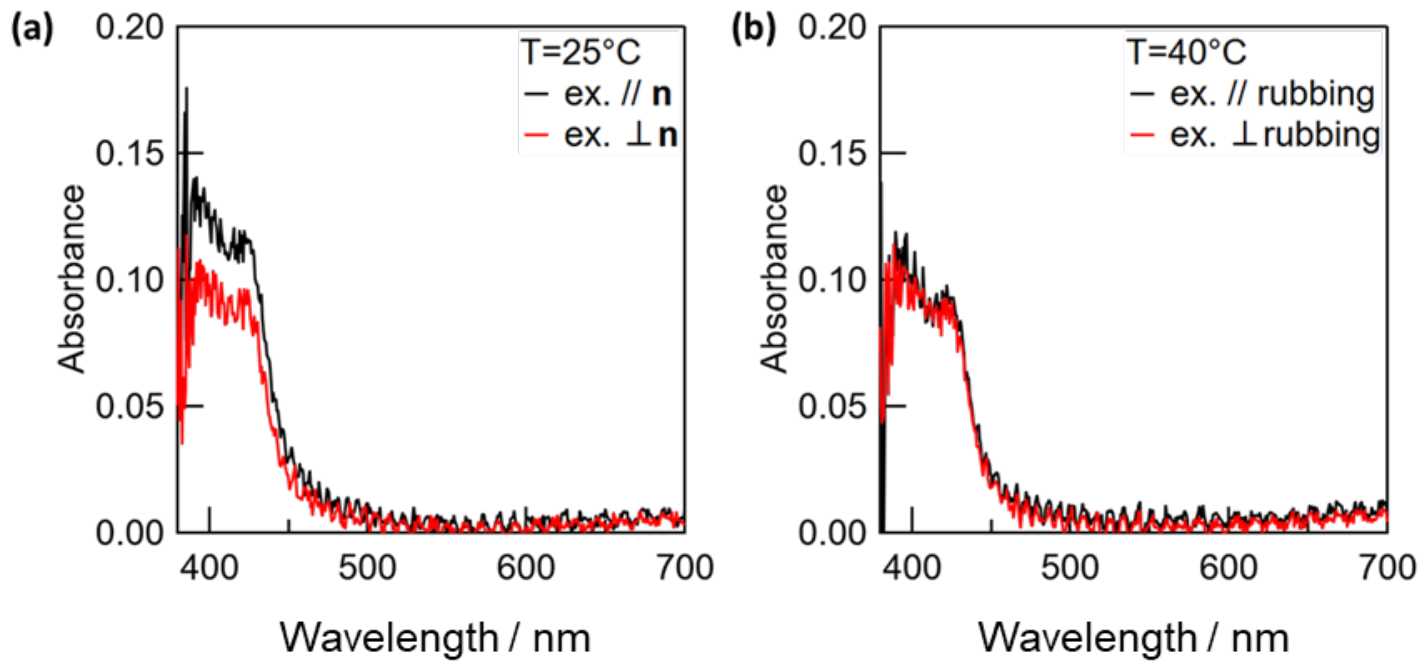

Figure S3-2. (a) Polarized absorbance spectra of FLAP0 doped at a concentration of $1 \mathrm{wt} \%$ in $5 \mathrm{CB}$, measured along (pol.//n) and perpendicular (pol. $\perp \mathbf{n}$ ) to the director of $5 \mathrm{CB}$ in the nematic phase $\left(25^{\circ} \mathrm{C}\right)$. (b) Polarized absorbance spectra measured in the isotropic phase $\left(40^{\circ} \mathrm{C}\right)$, where the polarizations are written with reference to the rubbing axis on the substrate.

Note: We found that FLAP0 doped in 5CB has a small anisotropy in the longer wavelength region of the absorption spectrum $(\lambda>400 \mathrm{~nm})$, in which $5 \mathrm{CB}$ has no absorption, indicating that the ground-state direction of FLAP0 is not completely isotropic. 
(a)

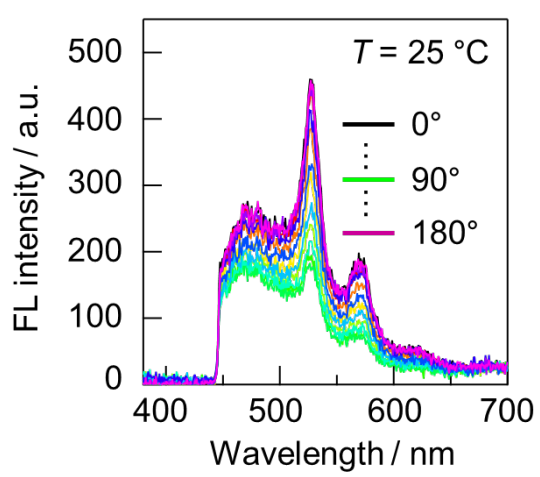

(b)

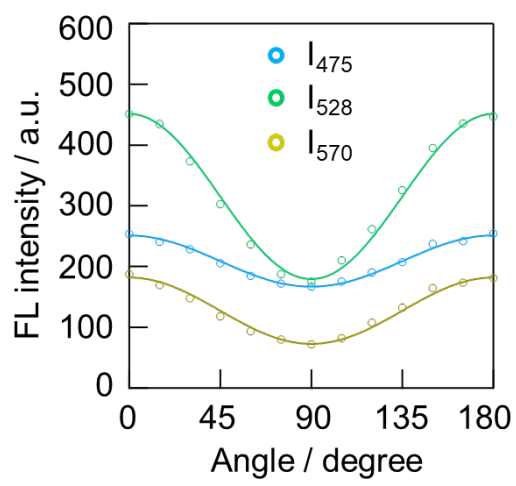

(c)

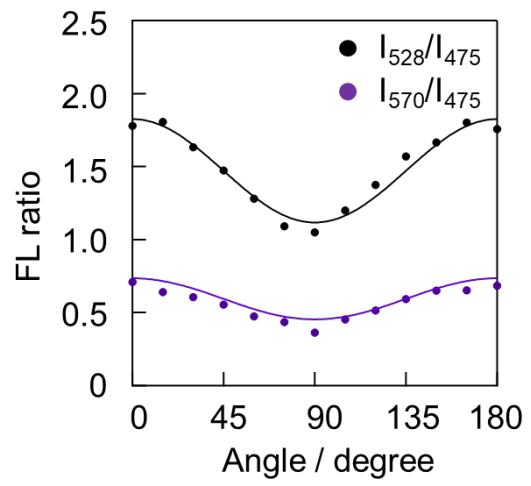

Figure S3-3. (a) Polarization-resolved FL spectra (non-polarized excitation, $\lambda_{\mathrm{ex}}=380 \mathrm{~nm}$ ) of FLAP0 doped in 5CB $(0.5 \mathrm{wt} \%)$ in the nematic phase $\left(25^{\circ} \mathrm{C}\right)$, where the polarization angle is measured from the director axis. (b) Dependence of the FL peak intensities on the polarizer angle. (c) Polarization dependence of the FL intensity ratios attributed to the planarized $(528,570 \mathrm{~nm})$ and V-shaped $(475 \mathrm{~nm})$ FLAP0 species in the $\mathrm{S}_{1}$ excited state.

(a)

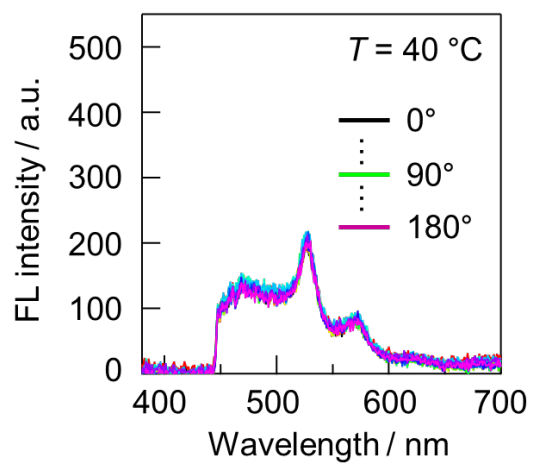

(b)

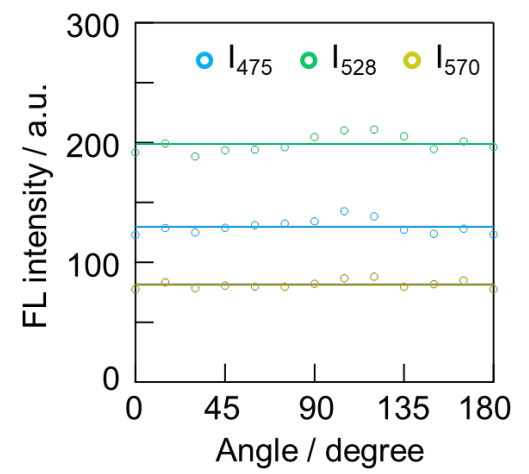

(c)

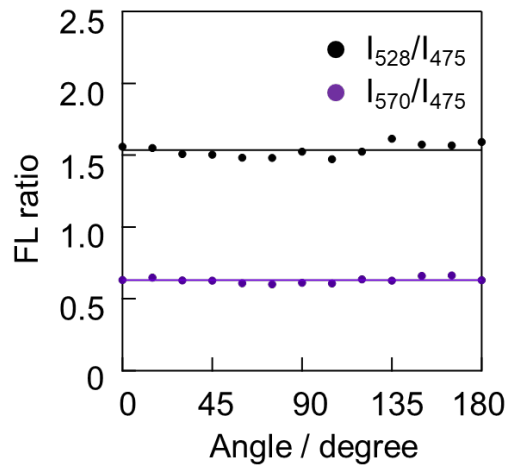

Figure S3-4. (a) Polarization-resolved FL spectra (non-polarized excitation, $\lambda_{\mathrm{ex}}=380 \mathrm{~nm}$ ) of FLAP0 doped in 5CB $(0.5 \%)$ in the isotropic phase $\left(40^{\circ} \mathrm{C}\right)$. The polarization angle is measured from the rubbing axis on the cell substrates. (b) Dependence of the FL peak intensities on the polarization angle. (c) Polarization dependence of the FL intensity ratios attributed to the planarized $(528,570 \mathrm{~nm})$ and V-shaped $(475 \mathrm{~nm})$ FLAP0 species in the $\mathrm{S}_{1}$ excited state. 


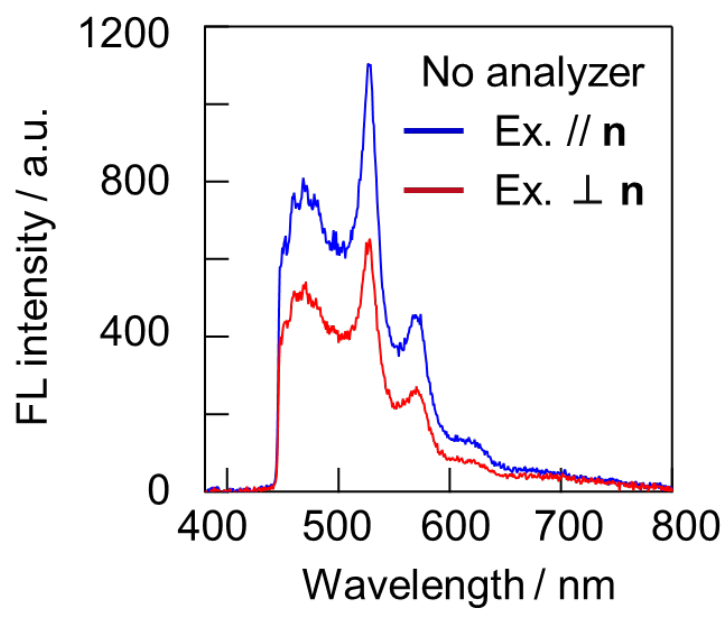

\begin{tabular}{lccc}
\hline & Ex. $/ / \mathbf{n}$ & Ex. $\perp \mathbf{n}$ & Ratio[a] \\
\hline$I_{527} / I_{470}$ & 1.36 & 1.19 & 0.88 \\
$I_{570} / I_{470}$ & 0.57 & 0.50 & 0.87 \\
\hline
\end{tabular}

[a] $\left(I_{527} / I_{470}\right.$ in Ex. $\left.\perp \mathbf{n}\right) /\left(I_{527} / I_{470}\right.$ in Ex. $\left./ / \mathbf{n}\right)$ or $\left(I_{570} / I_{470}\right.$ in Ex. $\left.\perp \mathbf{n}\right) /\left(I_{570} / I_{470}\right.$ in Ex. $\left./ / \mathbf{n}\right)$

Figure S3-5. FL spectra and FL ratios of FLAP0 in $5 \mathrm{CB}(0.5 \mathrm{wt} \%)$ at $25{ }^{\circ} \mathrm{C}$ excited with a polarized light $\left(\lambda_{\mathrm{ex}}=380\right.$ $\mathrm{nm})$ but detected with the analyzer removed. Ex.//n and Ex. $\perp \mathbf{n}$ indicate excitation polarizations parallel and perpendicular to the $5 \mathrm{CB}$ director, respectively.

Note: When FLAP0 was excited with a polarized light and the FL was detected without an analyzer, the FL ratio showed a significant dependence on the polarization angle of the excitation light. This means that the degree of the suppression of the planarization dynamics is dependent on the direction of the V-shaped FLAP0 in the ground state relative to the director of $5 \mathrm{CB}$.
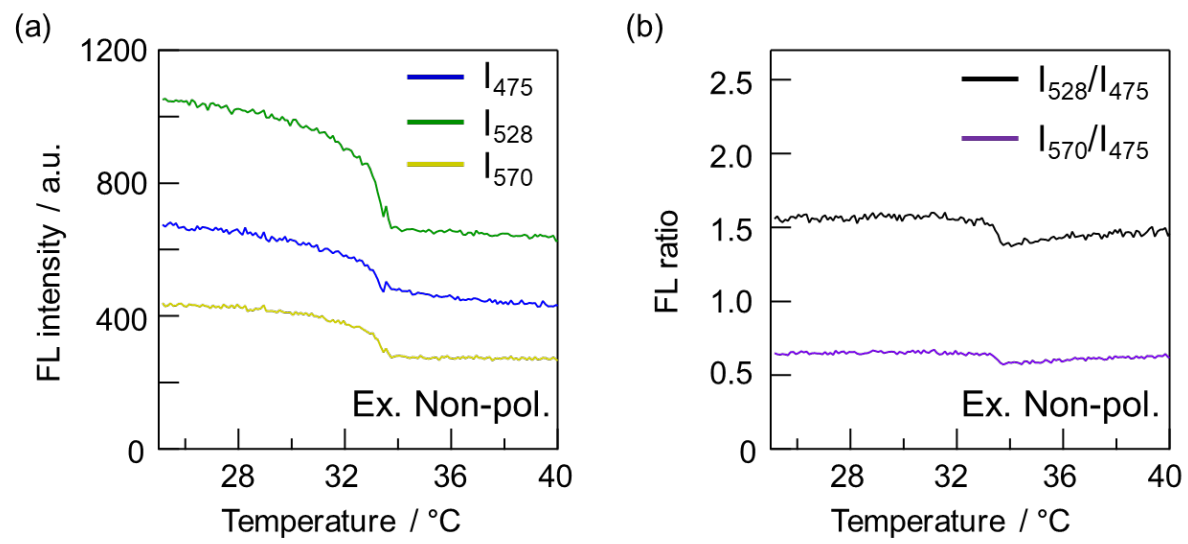

Figure S3-6. Temperature dependence of (a) the FL intensities and (b) the FL ratios of FLAP0 doped in 5CB (0.5 $\mathrm{wt} \%)$ excited with a non-polarized light $\left(\lambda_{\mathrm{ex}}=380 \mathrm{~nm}\right)$ and detected without passing a polarizer. A kink is observed in the FL ratio at approx. $34{ }^{\circ} \mathrm{C}$, demonstrating ratiometric detection of the phase transition by FLAP0. 


\section{Density functional theory (DFT) calculations}

DFT calculations of the isolated molecules were performed using the Gaussian 16 program. ${ }^{[55]} \mathrm{Kohn}-\mathrm{Sham}$ orbitals were displayed by the Avogadro program. ${ }^{[\mathrm{S6}]}$ A model structure (FLAP0') has hydrogen atoms in place of the 2,6-diisopropylphenyl groups of the corresponding molecule (Figure S4-1).

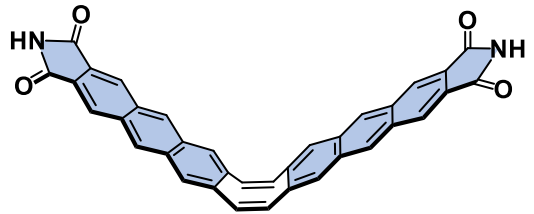

Figure S4-1. The model compound FLAP0' for the DFT calculations.

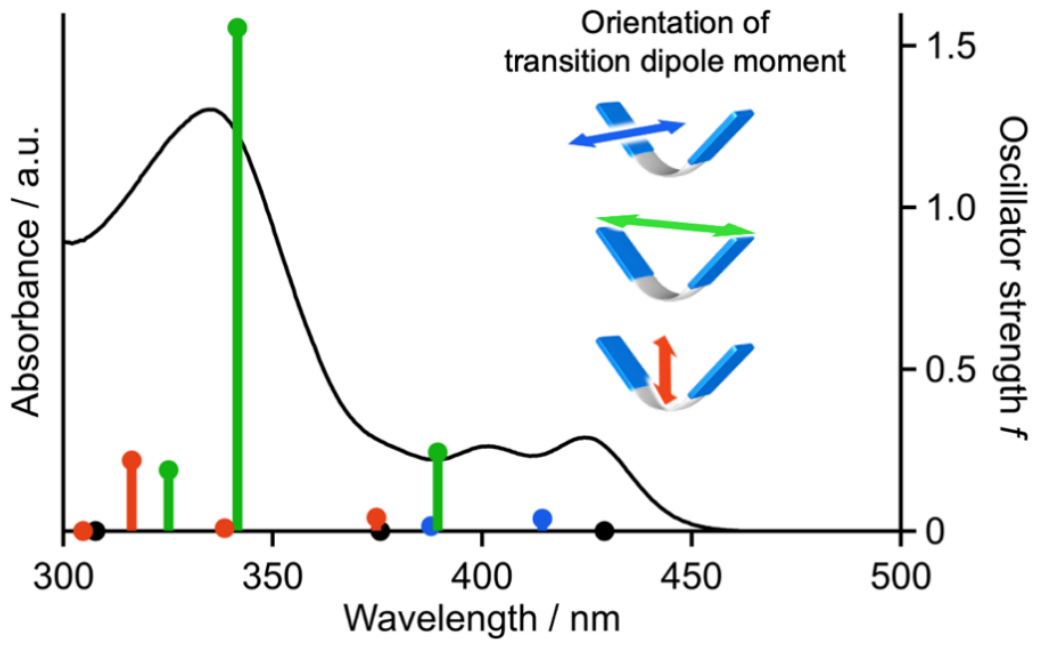

Figure S4-2. Oscillator strengths of $\mathrm{S}_{0} \rightarrow \mathrm{S}_{\mathrm{n}}$ transitions of FLAP0' (optimized geometry in $\mathrm{S}_{0}$ ) calculated at the TDPBE0/6-31+G(d) level (bars) and observed UV-visible absorption spectrum (line) of FLAP0 in PhCN. 
Table S4-1. Excitation energies and oscillator strengths for FLAP0' (optimized geometry in $\mathrm{S}_{0}$ ) calculated at the TD-PBE0 /6-31+G(d) level.

\begin{tabular}{|c|c|c|c|c|}
\hline Transition & Excitation energy & Configurations & $f$ & $\begin{array}{c}\text { Orientation of } \\
\text { transition dipole moment }\end{array}$ \\
\hline $\mathrm{S}_{0} \rightarrow \mathrm{S}_{1}$ & $2.89 \mathrm{eV}(429 \mathrm{~nm})$ & HOMO $\rightarrow$ LUMO (96\%) & 0 & - \\
\hline $\mathrm{S}_{0} \rightarrow \mathrm{S}_{2}$ & $2.99 \mathrm{eV}(414 \mathrm{~nm})$ & $\begin{array}{l}\mathrm{HOMO} \rightarrow \text { LUMO+1 }(92 \%) \\
\mathrm{HOMO}-1 \rightarrow \text { LUMO }(7 \%)\end{array}$ & 0.0382 & \\
\hline \multirow{3}{*}{$\mathrm{S}_{0} \rightarrow \mathrm{S}_{3}$} & \multirow{3}{*}{$3.18 \mathrm{eV}(389 \mathrm{~nm})$} & $\mathrm{HOMO} \rightarrow \mathrm{LUMO}+2(70 \%)$ & \multirow{3}{*}{0.2438} & \\
\hline & & HOMO-2 $\rightarrow$ LUMO (16\%) & & \\
\hline & & HOMO-1 $\rightarrow$ LUMO+3 (8\%) & & \\
\hline \multirow{2}{*}{$\mathrm{S}_{0} \rightarrow \mathrm{S}_{4}$} & \multirow{2}{*}{$3.20 \mathrm{eV}(388 \mathrm{~nm})$} & HOMO-1 $\rightarrow$ LUMO (92\%) & \multirow{2}{*}{0.0153} & \\
\hline & & $\mathrm{HOMO} \rightarrow \mathrm{LUMO}+1(7 \%)$ & & \\
\hline $\mathrm{S}_{0} \rightarrow \mathrm{S}_{5}$ & $3.30 \mathrm{eV}(376 \mathrm{~nm})$ & $\mathrm{HOMO}-1 \rightarrow \mathrm{LUMO}+1$ (96\%) & 0 & \\
\hline \multirow{3}{*}{$\mathrm{S}_{0} \rightarrow \mathrm{S}_{6}$} & \multirow{3}{*}{$3.31 \mathrm{eV}(375 \mathrm{~nm})$} & $\mathrm{HOMO} \rightarrow \mathrm{LUMO}+3(37 \%)$ & \multirow{3}{*}{0.0421} & \\
\hline & & $\mathrm{HOMO}-1 \rightarrow \mathrm{LUMO}+2(29 \%)$ & & \\
\hline & & $\mathrm{HOMO}-2 \rightarrow \mathrm{LUMO}+1(24 \%)$ & & \\
\hline \multirow{2}{*}{$\mathrm{S}_{0} \rightarrow \mathrm{S}_{7}$} & \multirow{2}{*}{$3.63 \mathrm{eV}(342 \mathrm{~nm})$} & HOMO-2 $\rightarrow$ LUMO (75\%) & \multirow{2}{*}{1.5553} & \\
\hline & & $\mathrm{HOMO} \rightarrow \mathrm{LUMO}+2(22 \%)$ & & \\
\hline \multirow{2}{*}{$\mathrm{S}_{0} \rightarrow \mathrm{S}_{8}$} & \multirow{2}{*}{$3.66 \mathrm{eV}(339 \mathrm{~nm})$} & $\mathrm{HOMO} \rightarrow \mathrm{LUMO}+3(53 \%)$ & \multirow{2}{*}{0.0089} & \\
\hline & & $\mathrm{HOMO}-1 \rightarrow \mathrm{LUMO}+2(41 \%)$ & & \\
\hline
\end{tabular}




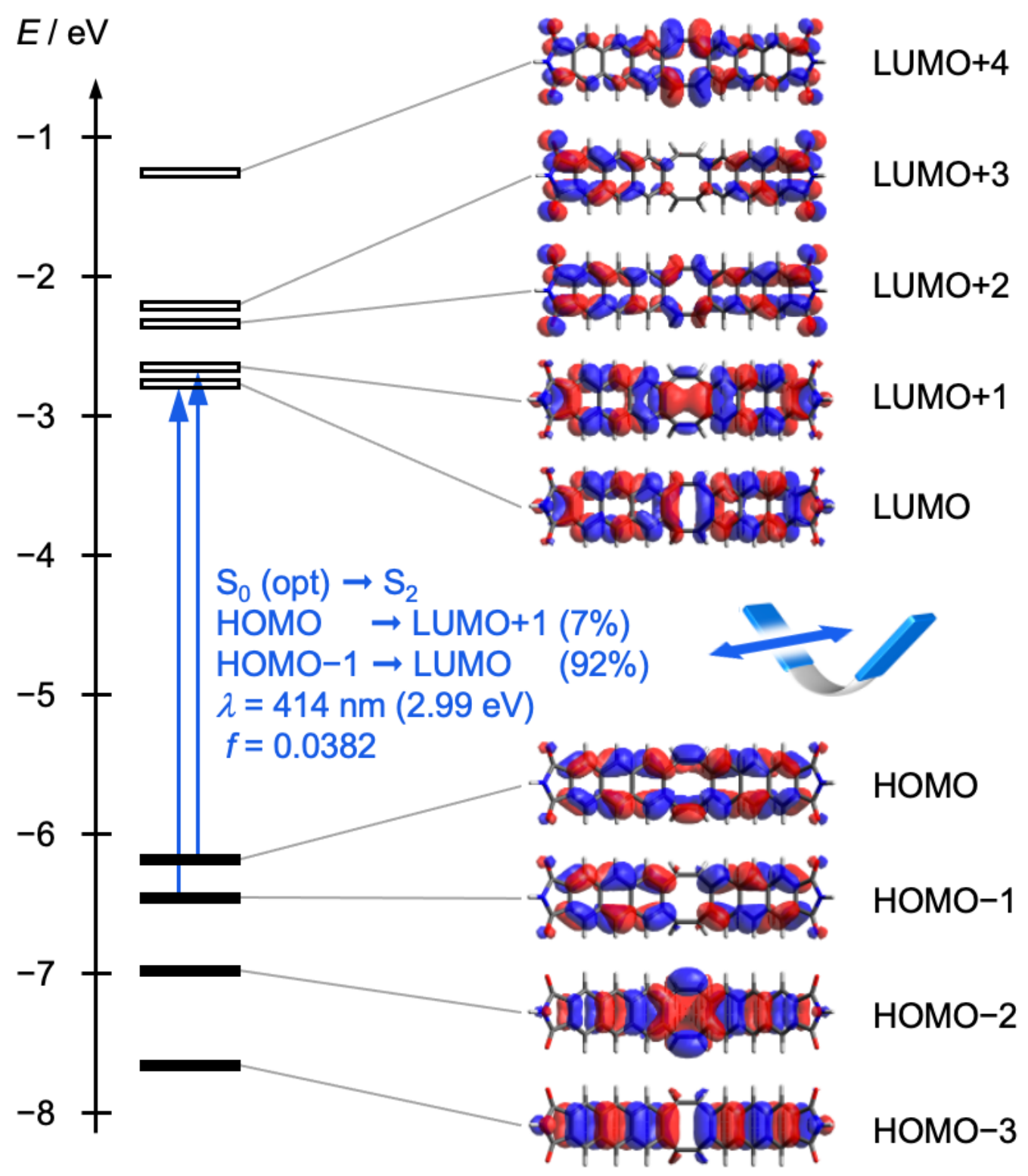

Figure S4-3. Kohn-Sham molecular orbitals of FLAP0' in the $\mathrm{S}_{0}$ optimized geometry $\left(C_{2 \mathrm{v}}\right.$ symmetry, COT bending angle $\theta=41.1^{\circ}$ ) and the transition character of the absorption in the longest wavelength region, calculated at the (TD-)PBE0/6-31+G(d) level. See the reference [S2] for the definition of the COT bending angle. 


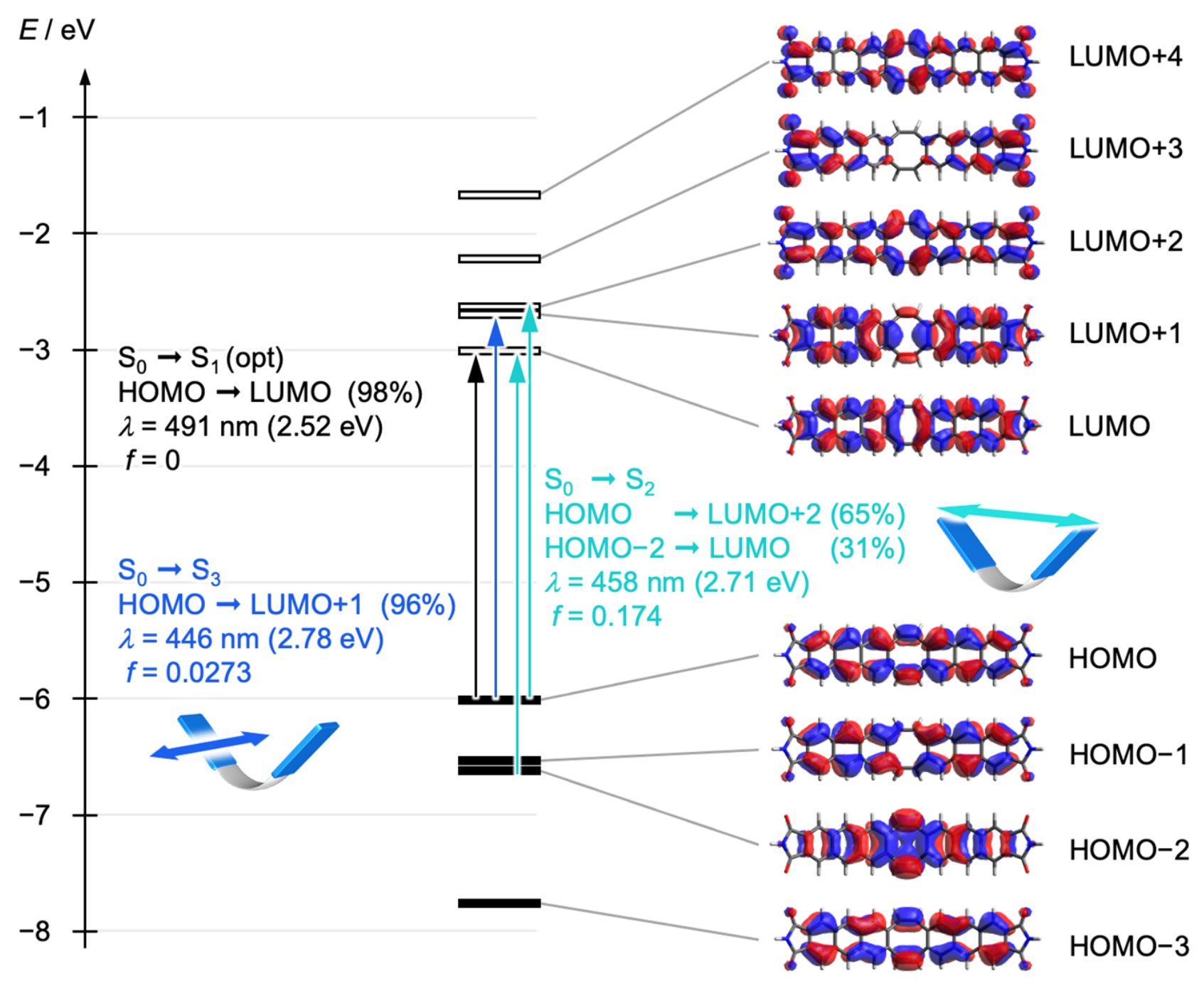

Figure S4-4. Kohn-Sham molecular orbitals of FLAP0' with the shallow V-shaped structure $\left(C_{2 v}\right.$ symmetry $)$ at the $\mathrm{S}_{1}$ local minimum (COT bending angle $\theta=28.2^{\circ}$ ) and the transition characters, calculated at the TD-PBE0/6-31+G(d) level. See the reference [S2] for the definition of the COT bending angle. 


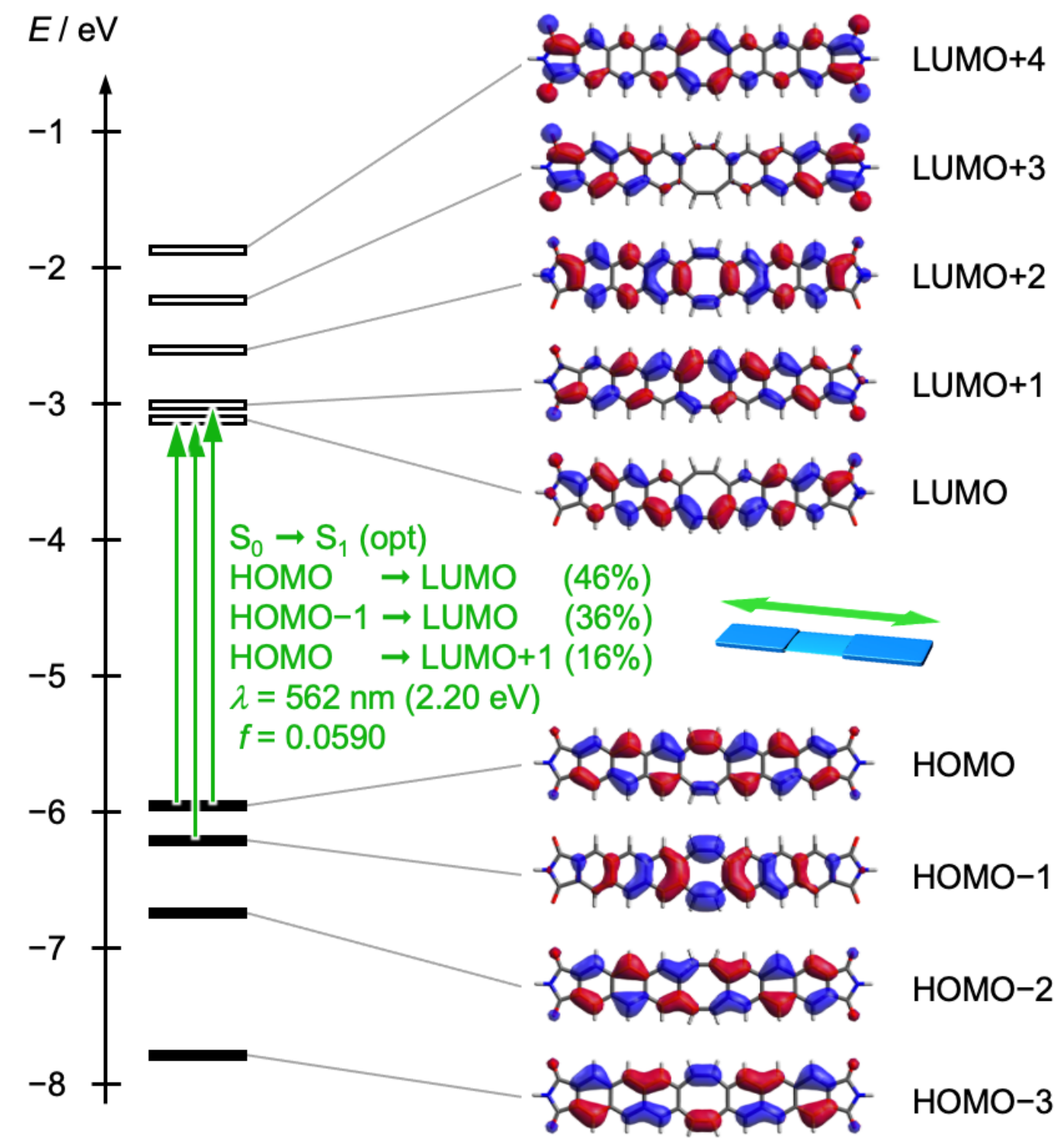

Figure S4-5. Kohn-Sham molecular orbitals of FLAP0' with the planar structure $\left(C_{2 \mathrm{v}}\right.$ symmetry) at the $\mathrm{S}_{1}$ global minimum (COT bending angle $\theta=0^{\circ}$ ) and the transition character of the fluorescence, calculated at the TD-PBE0/6$31+\mathrm{G}(\mathrm{d})$ level. See the reference [S2] for the definition of the COT bending angle. 


\section{Supporting references}

S1. R. Kotani, H. Sotome, H. Okajima, S. Yokoyama, Y. Nakaike, A. Kashiwagi, C. Mori, Y. Nakada, S. Yamaguchi, A. Osuka, A. Sakamoto, H. Miyasaka and S. Saito, J. Mater. Chem. C 2017, 5, 5248.

S2. R. Kimura, H. Kuramochi, P. Liu, T. Yamakado, A. Osuka, T. Tahara and S. Saito, Angew. Chem. Int. Ed. 2020, 59,16430

S3. M. K. Kuimova, G. Yahioglu, J. A. Levitt and K. Suhling, J. Am. Chem. Soc. 2008, 130, 6672.

S4. W. Nakanishi, S. Saito, N. Sakamoto, A. Kashiwagi, S. Yamaguchi, H. Sakai and K. Ariga, Chem. Asian J. 2019, 14, 2869.

S5. Gaussian 16, Revision A.03, M. J. Frisch, G. W. Trucks, H. B. Schlegel, G. E. Scuseria, M. A. Robb, J. R. Cheeseman, G. Scalmani, V. Barone, G. A. Petersson, H. Nakatsuji, X. Li, M. Caricato, A. V. Marenich, J. Bloino, B. G. Janesko, R. Gomperts, B. Mennucci, H. P. Hratchian, J. V. Ortiz, A. F. Izmaylov, J. L. Sonnenberg, D. Williams-Young, F. Ding, F. Lipparini, F. Egidi, J. Goings, B. Peng, A. Petrone, T. Henderson, D. Ranasinghe, V. G. Zakrzewski, J. Gao, N. Rega, G. Zheng, W. Liang, M. Hada, M. Ehara, K. Toyota, R. Fukuda, J. Hasegawa, M. Ishida, T. Nakajima, Y. Honda, O. Kitao, H. Nakai, T. Vreven, K. Throssell, J. A. Montgomery, Jr., J. E. Peralta, F. Ogliaro, M. J. Bearpark, J. J. Heyd, E. N. Brothers, K. N. Kudin, V. N. Staroverov, T. A. Keith, R. Kobayashi, J. Normand, K. Raghavachari, A. P. Rendell, J. C. Burant, S. S. Iyengar, J. Tomasi, M. Cossi, J. M. Millam, M. Klene, C. Adamo, R. Cammi, J. W. Ochterski, R. L. Martin, K. Morokuma, O. Farkas, J. B. Foresman, and D. J. Fox, Gaussian, Inc., Wallingford CT, 2016.

S6. M. D. Hanwell, D. E. Curtis, D. C. Lonie, T. Vandermeersch, E. Zurek and G. R. Hutchison, J. Cheminfomatics 2012, 4, 17. 